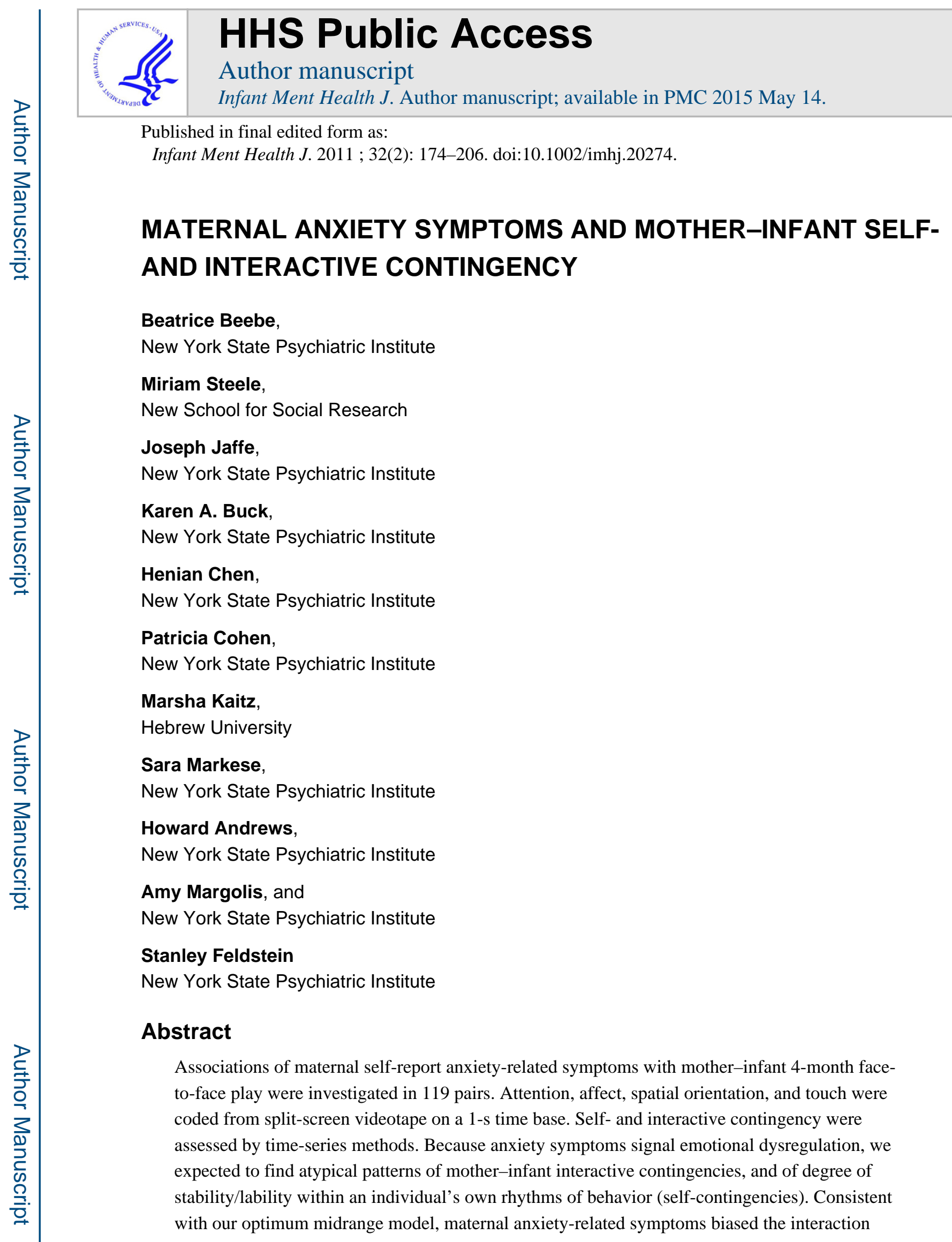

Direct correspondence to: Beatrice Beebe, New York State Psychiatric Institute, No. 108, 1051 Riverside Drive, New York, NY, 10032; beebebe@pi.cpmc.columbia.edu. 
toward interactive contingencies that were both heightened (vigilant) in some modalities and lowered (withdrawn) in others; both may be efforts to adapt to stress. Infant self-contingency was lowered ("destabilized") with maternal anxiety symptoms; however, maternal self-contingency was both lowered in some modalities and heightened (overly stable) in others. Interactive contingency patterns were characterized by intermodal discrepancies, confusing forms of communication. For example, mothers vigilantly monitored infants visually, but withdrew from contingently coordinating with infants emotionally, as if mothers were "looking through" them. This picture fits descriptions of mothers with anxiety symptoms as overaroused/fearful, leading to vigilance, but dealing with their fear through emotional distancing. Infants heightened facial affect coordination (vigilance), but dampened vocal affect coordination (withdrawal), with mother's face - a pattern of conflict. The maternal and infant patterns together generated a mutual ambivalence.

Face-to-face play elicits the infant's most advanced communication capacities, and its developmental importance is widely recognized (Field, 1995; Jaffe, Beebe, Feldstein, Crown, \& Jasnow, 2001; Lewis \& Feiring, 1989; Malatesta, Culver, Tesman, \& Shepard, 1989; Tronick 1989). The negative effects of postnatal maternal depressive symptoms on mother-infant communication and child development have been extensively documented (Cohn, Campbell, Matias, \& Hopkins, 1990; Field, 1995; Murray, Fiori-Cowley, Hooper, \& Cooper, 1996; Tronick, 1989). But little work has investigated the effects of maternal anxiety-related symptoms on mother-infant face-to-face play in early infancy, the subject of this report.

Whereas attention to the effects of prenatal maternal anxiety symptoms has increased (O’Connor, Heron, Golding, Beveridge \& Glover, 2002), the effects of postnatal maternal anxiety symptoms in early infancy remain less examined (Kaitz \& Maytal, 2005; Matthey, Barnett, Howie, \& Kavanagh, 2003; Miller, Pallant, \& Negri, 2006). Britton (2005) noted that even moderate postpartum maternal anxiety is associated with adverse parenting. Anxious mothers evidence diminished feelings of efficacy in the parenting role (Gondoli \& Silverber,1997; Porter \& Hsu, 2003), reduced coping capacity (Barnett \& Parker, 1986), decreased behavioral competence (Teti \& Gelfand, 1991), reduced positive emotional tone (Nicol-Harper, Harvey, \& Stein, 2007), less warmth and more criticism (Weinberg \& Tronick, 1998), more intrusion (Feldman, 2007; Weinberg \& Tronick, 1998, Wijnroks, 1999), and less active engagement (Murray, Cooper, Creswell, Schofield, \& Sack, 2007). Infants of anxious mothers cry more (Papousek \& von Hofacker, 1998). Mothers with comorbid depression and anxiety symptoms (vs. depressed mothers) are less positive (less smiling, less exaggerated facial expressiveness, less game-playing and imitating); their infants spend less time smiling and more time in distressed brow and crying (Field et al., 2005).

Weinberg and Tronick (1998) reported that psychiatrically ill mothers (panic disorder, major depressive disorder, or obsessive-compulsive disorder) versus controls are more disengaged with their infants in face-to-face play (less vocalizing, fewer interest expressions, less touch, and less shared focus of attention on objects). During the reunion episode of the still-face paradigm with mother, as well as during an interaction with strangers, proband infants were more negative (less interest, more anger and sadness, more fuss/cry), indicating more 
difficulty repairing the interaction after the disruption. The strangers were more disengaged (less touching, greater physical distance) when interacting with proband infants.

Reduced maternal sensitivity has been associated with maternal anxiety symptoms in some studies (Feldman, Greenbaum, Mayes, \& Erlich, 1997; Nicol-Harper et al., 2007; Warren et al., 2003), especially when infants have high negative affect (Mertesacker, Bade, Haverkock, \& Pauli-Pott, 2004). But other studies have failed to find reduced maternal sensitivity (Kaitz, Maytal, Devor, Bergman, \& Mankuta, 2010; Murray et al., 2007). Feldman (2007) found increased maternal intrusion and lower infant social involvement in more anxious mothers during 4-month face-to-face interaction. Weinberg, Beeghly, Olson, and Tronick (2008) failed to find any differences in anxious mothers or their infants at 6 months. Kaitz et al. (2010) found that anxious mothers showed more exaggerated behaviors and that their infants showed less negative affect in the still-face and reunion episodes of the still-face paradigm; but otherwise, there were no maternal or infant differences despite detailed microanalytic video coding and extensive testing. Warren et al. (2003) found no differences during face-to-face communication in infants of panic disorder mothers, but did document increased infant cortisol levels. Murray et al. (2007) found no behavioral differences in infants of socially phobic mothers at 10 weeks, but infants were less responsive to a stranger.

Whereas many of these studies have highlighted the importance of maternal anxiety symptoms for child development, there is still relatively little detailed description of the effects of maternal anxiety symptoms on early mother-infant face-to-face communication. Where studies have begun to analyze communication in detail, results have been absent, scarce, or contradictory. Thus, more detailed description is needed to understand the nature of communication disturbances that may be associated with maternal anxiety-related symptoms.

\section{A DYADIC SYSTEMS VIEW OF COMMUNICATION}

A dyadic systems view of face-to-face communication informs our research (Beebe \& Lachmann, 2002; Jaffe et al., 2001). Because each person must monitor and coordinate with the partner, as well as regulate inner state, in this view all interactions are a simultaneous product of self-and interactive processes (Gianino \& Tronick, 1988; Sander, 1977; Thomas \& Martin, 1976; Tronick, 1989). Fogel (1993) described all behavior as unfolding in the individual while also modifying and being modified by the changing behavior of the partner. Although rarely studied together, both self- and interactive processes are essential to communication. Both intrapersonal and interpersonal behavioral rhythms provide the ongoing temporal information necessary to predict and coordinate with one's partner, so that each can anticipate how the other will proceed (Feldman, 2006; Warner, 1992). ${ }^{1}$

We study self- and interactive processes with measures of "contingency," a term we use interchangeably with "predictability" and "coordination." Contingencies are defined as predictability of behavior over time, analyzed by time-series techniques. Interactive contingency picks up consistently occurring, moment-to-moment adjustments that each individual makes to changes in partner behavior. It is defined as the predictability of each 
partner's behavior from that of the other, over time (lagged cross-correlation), translated into the metaphor of expectancies of "how I affect you," and "how you affect me." Selfcontingency (auto-correlation) indexes the degree to which any prior state predicts the next observed state, and is considered one form of self-regulatory process (Thomas \& Malone, 1976; Warner, 1992). It is interpreted as the stability/lability of each person's own behavior over time, in the presence of a particular partner.

Contingency processes are the foundation of social communication. Contingency in social behavior reduces uncertainty about what is likely to happen next (Warner, 1992). By 4 months, infants are adept at perceiving contingent relations, as well as discriminating degrees thereof, and generating expectancies (predictions) based upon them (DeCasper \& Carstens, 1980; Haith, Hazan, \& Goodman, 1988; Watson, 1985). They are highly sensitive to the ways in which their behaviors are contingently responded to (DeCasper \& Carstens, 1980; Hains \& Muir, 1996; Haith et al., 1988; Murray \& Trevarthen, 1985; Tarablusy, Tessier, \& Kappas, 1996; Watson, 1985). The nature of each partner's contingent coordination with the other, termed "mutual regulation" by Tronick (1989), affects the infant's ability to attend, process information, and modulate behavior and emotional state (Hay, 1997). Contingency processes are essential to the creation of infant and maternal social expectancies and interactive efficacy, and infant cognitive and social development (Feldman, 2007; Hay, 1997; Lewis \& Goldberg, 1969; Murray \& Cooper, 1997; Trevarthen, 1977; Tronick, 1989).

\section{THE MEANING OF HIGHER AND LOWER DEGREES OF SELF- AND INTERACTIVE CONTINGENCY}

Contradictory theories of the meaning of interactive contingency have proposed that (a) high coordination is optimal for communication (Chapple, 1970), (b) high coordination indexes communicative distress (Gottman, 1979), or (c) our position (Beebe et al., 2007; Beebe et al., 2008a; Jaffe et al., 2001), an optimal midrange model in which both excessive and insufficient coordination index social distress (see Cohn \& Elmore, 1988; Kaitz \& Maytal, 2005; Warner, Malloy, Schneider, Knoth, \& Wiler, 1987). Social experiences that force the infant to pay too much or too little attention to the partner may disturb the infant's ability to modulate his or her emotional state while processing information, and are likely to disturb social and cognitive development (Hay, 1997).

Our previous work has documented that high or low poles of interactive contingency during mother-infant face-to-face play predicted attachment insecurity (Beebe et al., 2010; Jaffe et al., 2001; Markese, Beebe, Jaffe, \& Feldstein, 2008), maternal depression (Beebe et al., 2008a), and maternal self-criticism and dependency (Beebe et al., 2007). Other research has converged on such a model, in which distress biases the system toward both heightened interactive contingency (in some modalities) and lowered (in others) (Belsky, Rovine, \& Taylor, 1984; Hane, Feldstein, \& Dernetz, 2003; Leyendecker, Lamb, Fracasso, Scholmerich, \& Larson, 1997; Lewis \& Feiring, 1989; Malatesta et al., 1989; Roe, Roe, Drivas, \& Bronstein, 1990). 
We interpret heightened interactive contingency as an effort to create more predictability in contexts of novelty, challenge, or threat, translated into "activation" or "vigilance." Vigilance for social signals is an important aspect of social intelligence, likely an evolutionary advantage with uncertainty or threat (Ohman, 2002). Clinically, this picture might translate into a mother who is "trying too hard" or "following too closely." We interpret low coordination as "inhibition" or "withdrawal," where metaphorically each partner is relatively "alone" in the presence of the other (Beebe et al., 2000; Jaffe et al., 2001). The partner's lowered interactive contingency compromises the individual's ability to anticipate consequences of his or her own actions for the partner, lowering interactive agency. Mothers and infants heighten and/or lower their self-and interactive contingencies not out of conscious intention but based on procedurally organized action sequences. Our use of the term procedural includes a view of the infant as an active agent in the construction of procedural knowledge.

Self-contingency has seen little study. Whereas other researchers have either ignored selfcontingency (e.g., Stern, 1971) or removed it statistically (Cohn \& Tronick, 1988; Jaffe et al., 2001), we treat it as a variable in its own right (see Badalamenti \& Langs, 1990; Crown et al., 1996; Thomas \& Malone, 1979; Warner, 1992). When one's ongoing behavioral stream is less predictable, we infer lowered ability to anticipate one's next move, a "destabilization." In contrast, heightened self-contingency indicates behavior tending toward an overly steady, nonvarying process, translated into the metaphor of "self-stabilization."

In examining vocal rhythms in adult conversations of unacquainted pairs, Warner (1992) found lowered self-contingency associated with lowered contingent coordination with the partner's behavior, and with a less positive evaluation of the conversation. Our prior work has shown primarily lowered self-contingency associated with maternal depression and selfcriticism. However, we found heightened as well as lowered infant self-contingency associated with infant disorganized attachment, and heightened infant self-contingency in the context of the novel stranger (Beebe et al., 2007; Beebe et al., 2008a; Beebe et al., 2010; Beebe et al., 2009). Thus, both poles of heightened and lowered self-contingency may be problematic.

\section{COMMUNICATION MODALITIES}

Face-to-face communication generates multiple simultaneous emotional signals which, although typically congruent, may be discordant in the context of disturbance (Shackman \& Pollak, 2005). Using detailed video microanalysis, we investigate whether specific modalities of the face-to-face exchange (attention, affect, touch, and spatial orientation) differ in patterns of self- and interactive contingency, defining different aspects of disturbance. Building on our prior findings examining maternal depression (Beebe et al., 2008a) and infant disorganized attachment (Beebe et al., 2010), we hypothesize that distress in either partner may be associated with intermodal discordances, generating confusing communication patterns. Only examination of separate modalities can identify such discordances (also see Bahrick, Hernandez-Reif, \& Flom, 2005; Keller, Lohaus, Volker, Cappenberg, \& Chasiotis, 1999; Van Egeren, Barratt, \& Roach, 2001; Weinberg \& Tronick, 1994; Yale, Messinger, Cobo-Lewis, \& Delgado, 2003). For example, in our prior work, 
depressed (vs. control) mothers showed lowered gaze, but heightened facial, contingent coordination with their infants (Beebe et al., 2008a).

Using separate modalities, we analyze visual attention (gaze), affect (facial and vocal), touch, and orientation. Gaze, facial affect, and vocalization have been well studied, and mothers are contingently responsive to infants in these modalities (Bigelow, 1998; Cohn \& Tronick, 1988; Keller et al., 1999; Van Egeren et al., 2001). Infants are sensitive to variations in the form, intensity, and timing of adult gaze and facial and vocal behavior, and are capable of coordinating with them to apprehend attentional and affective states (Gusella, Muir, \& Tronick, 1988; Jaffe et al., 2001; Messinger, 2002; Muir \& Hains, 1993; Murray \& Cooper, 1997; Stern, 1985; Trevarthen, 1977; Tronick, 1989).

Infant touch is important for infant self-soothing (Tronick, 1989; Weinberg \& Tronick, 1994). In studies of face-to-face interaction, infants use more self-touch (a) during the stillface experiment (Weinberg \& Tronick, 1996), (b) when mother leaves the room or a stranger enters (Trevarthen, 1977), (c) when infants view a noncontingent "replay" of the mother's behavior (Murray \& Trevarthen, 1985), or (d) when infants will be classified Avoidant Attachment at 12 months (Koulomzin et al., 2002).

Affectionate to intrusive patterns of maternal touch are a central, but less examined, modality (Feldman, 2007; Field, 1995; Moreno, Posada, \& Goldyn, 2006; Stepakoff, Beebe, \& Jaffe, 2000; Stack, 2001). Van Egeren et al. (2001) documented bidirectional contingency between mother touch and infant vocalization. Maternal touch can compensate when facial or vocal communication is not available, as in the still-face experiment (Pelaez-Nogueras, Field, Hossain, \& Pickens, 1996; Stack \& Arnold, 1998; Stack \& Muir, 1992). For example, self-critical mothers showed difficulty joining the infant's direction of gaze and difficulty entering the infant's emotional ups and downs, but compensated by becoming overly involved with touch, a more concrete modality than face or gaze (Beebe et al., 2007).

Maternal spatial orientation (sitting upright, leaning forward, looming in) and infant head orientation (from enface to arch) organize approach-avoid patterns which are central means of regulating proximity (Beebe \& Stern, 1977; Demetriades, 2003; Kushnick, 2002; Stern, 1971; Tronick, 1989). We did not analyze maternal vocal behavior. [Our automated vocal rhythm measure (Jaffe et al., 2001) will be used in a separate report.]

\section{APPROACH OF THE STUDY}

We generated six mother-infant "modality pairings," attempting to examine the same modality in both partners where possible (Pairings 1, 2, 5, and 6):

1. infant gaze-mother gaze

2. infant facial affect-mother facial affect

3. infant vocal affect-mother facial affect

4. infant vocal affect-mother touch

5. infant touch-mother touch 
6. infant head orientation-mother spatial orientation.

These six modality pairings address the four domains of visual attention (Pairing 1), affect (Pairings $2 \&$ 3), maternal touch (Pairings 4 \& 5), and spatial orientation (Pairing 6). We examine infant vocal affect as a second way of exploring infant emotional response to maternal facial affect (Hsu \& Fogel, 2003). We examine maternal touch in relation to infant vocal affect and touch, reasoning that infants may respond to intrusive touch with vocal distress or increased touch (see Van Egeren et al., 2001).

The specificity of this approach allows us to "unpack" interactions which might be coded as interactive errors (Tronick, 1989) or communication errors (Lyons-Ruth, Bronfman, \& Parsons, 1999). It identifies intermodal discrepancies, which may be intrapersonal or dyadic. Thus, this approach allows us to more clearly understand what the infant's experience might be. For example, we may identify difficulties in the regulation of attention, separate from the regulation of affect. Interactive contingency of gaze examines the degree to which each partner follows the direction of the other's visual attention, on and off the partner's face. Interactive contingency of affect was examined as two patterns of affective "mirroring," the degree to which partners share direction of affective change: (a) facial affect mirroring and (b) cross-modal maternal facial affect-infant vocal affect mirroring. The coordination of infant touch and maternal touch examines the degree to which, as infants touch more, mothers touch more affectionately (and vice versa) and whether the relative affectionate quality of maternal touch affects infant likelihood of touch (and vice versa). In this context, we can examine whether maternal touch might be a compensatory modality when attention or affect is problematic. Maternal contingent spatial coordination with infant head orientation measures mutual approach and withdrawal patterns (mother's likelihood of leaning forward or looming in as the infant reorients toward enface; and reciprocally, mother's likelihood of sitting back in an upright posture as the infant orients away). Infant head-orientation coordination with maternal spatial orientation measures the infant's likelihood of being involved in a maternal approach-infant withdrawal pattern (infant's likelihood of arching away as mother looms in Beebe \& Stern's, 1977, "chase and dodge" pattern, and reciprocally, the infant's likelihood of reorienting as mother sits back).

In this article, we investigate associations of maternal self-reported anxiety-related symptoms with mother-infant self- and interactive contingencies in the six modality pairings listed earlier. As a function of higher (vs. lower) maternal anxiety symptoms, we investigate (a) which partner (mother/infant) shows altered 4-month contingency, (b) the type of contingency (self/interactive) that is altered, (c) whether contingency is increased or decreased, and (d) the modality of contingency that is altered. We also explore whether maternal anxiety symptoms are associated with differences in qualitative features of behavior (e.g., intrusive maternal touch).

We examine the effects of maternal anxiety symptoms irrespective of depressive-symptom status, following most previous studies, reflecting the high prevalence of comorbid anxious and depressive states (Austin, 2004; Heron, O'Connor, Evans, Golding, \& Glover, 2004; Kaufman \& Charney, 2000; Matthey et al., 2003; Miller et al., 2006). The anxiety symptoms of the assessment method we used, the State-Trait Anxiety Inventory (STAI; Spielberger, 
Gorsuch, \& Lushene, 1983), are not specific to anxiety or depression but they do reflect internal discomfort and likely heightened stress. Some researchers hold that the STAI indexes general distress and negative affectivity more so than anxiety specifically (Nitschke, Heller, Imig, McDonald, \& Miller, 2001; Pizzagalli et al., 2002). Thus, we do not address anxiety disorder, but a more general distress.

\section{HYPOTHESES}

Building on our documentation of an "optimal midrange" model of interactive contingency (Jaffe et al., 2001), in which both heightened and lowered degrees of vocal rhythm contingency predicted different categories of insecure attachment, we hypothesize that maternal anxiety symptoms bias mother-infant communication toward both heightened interactive contingency (in some modalities) and lowered (in others). Because we analyze each modality separately, heightened (or lowered) contingency with maternal anxiety will be evident in different modalities. For example, we previously documented that in dyads where mothers had higher depressive symptoms, mothers and infants had both higher contingencies (in affect) and lower contingencies (in gaze) than did dyads with lower maternal symptoms (Beebe et al., 2008a). Such findings are conceptually midrange, or consistent with our optimal midrange model, rather than statistically nonlinear. Similarly, because our prior work noted earlier has identified both heightened and lowered selfcontingency in contexts such as maternal distress, infant attachment insecurity, and the challenge of the novel stranger, we anticipate that in the context of maternal anxiety symptoms, we will find both heightened and lowered self-contingencies of both partners.

Building on our prior findings examining maternal depression and self-criticism, and infant disorganized attachment (Beebe et al., 2007; Beebe et al., 2008a; Beebe et al., 2010), we hypothesize that distress in either partner may be associated with intermodal discordances, generating confusing communication patterns.

In the absence of much literature, we hypothesize about heightened and/or lowered interactive contingencies in specific modalities. Building on Kaitz and Maytal's (2005) view that anxious mothers may be "underresponsive" (i.e., withdrawn, self-absorbed), dealing with their own fear and overarousal by emotional distancing, we anticipate that anxious mothers will show lowered interactive contingencies in affective modalities. Based on the suggestion that anxious mothers also may be "overreactive," and the concept that anxious mothers may be vigilant in response to their own fearfulness and overaroused inner state (Barlow, 1991; Kaitz \& Maytal, 2005), looking to see what will happen, we anticipate that these mothers will show heightened interactive contingencies in gaze. If there are difficulties in the regulation of affect or visual attention, as we expect, we anticipate mothers will compensate with heightened interactive contingency of touch (see Beebe et al., 2007; Pelaez-Nogueras et al., 1996; Stack \& Muir, 1992).

We anticipate that infants will show heightened contingent coordination with their mothers in some modalities, in an effort to process aspects of the mother's disturbed communication. Following de Rosnay, Cooper, Tsigaras, and Murray (2006), we anticipate that infants will be overly sensitive to maternal affective communications, showing heightened interactive 
contingencies in affective modalities. We also anticipate that infants will show lowered contingency with mothers in the other modalities, consistent with a description of infants of anxious mothers as withdrawn, or avoidant (Feldman, 2007; Kaitz \& Maytal, 2005). If these hypotheses are verified, combinations of both heightened and lowered interactive contingencies may yield intermodal discordances, generating confusing communication patterns, as proposed earlier.

In addition to process measures of contingency over time, we also used content measures of qualitative features of behavior. We hypothesize that maternal anxiety symptoms are associated with maternal intrusive touch and negative facial affect, and negative infant vocal affect reflecting distress/ irritability (de Rosnay et al., 2006; Feldman, 2007; Kaitz \& Maytal, 2005; Papousek \& von Hofacker, 1998; Weinberg \& Tronick, 1998).

\section{THE PROBLEM OF LOW SCORES IN SELF-REPORT SCALES}

Self-report scales constitute the central measurement of maternal distress in child development research. Such scales are vulnerable to "denial" of distress (Shedler, Mayman, \& Manis, 1993), so that low scores may be difficult to interpret. Using coronary reactivity, Schedler, Mayman, and Manis (1993) showed that some subjects with low self-report depression had lower coronary reactivity; but for subjects clinically judged "distressed," lower depression scores were correlated with higher coronary reactivity. Debate exists as to whether low-scoring mothers might be "denying" their distress. Pickens and Field (1993) showed that infants of low-scoring mothers (Beck Depression Inventory) had more negative facial expressions, whereas Tronick, Beeghly, Weinberg, and Olson (1997) argued that low scores on The Center for Epidemiological Studies Repression Scale (the CES-D) represented "postpartum exuberance." Lyons-Ruth, Zoll, Connell, and Grunebaum (1986) found that mothers who scored zero on the CES-D were high on covert hostility and interference during mother-infant interaction. Blank (1986) found that very low anxiety symptom scores (but not high) were associated with feeding difficulties and altered cortisol levels. Some mothers at the low end may indeed be distress-free whereas others may deny distress. Shedler et al. (1993) solved this problem with an independent measure of distress.

Consistent with Shedler et al. (1993), our prior work on maternal distress (depression, selfcriticism, and dependency; Beebe et al., 2007; Beebe et al., 2008a) showed that altered selfand interactive contingency patterns were similar at both high and low poles of distress (compared to dyads with mothers scoring midrange in distress), suggesting that both poles of scores may be problematic. We reasoned that some mothers volunteering for a study of infant social development may be motivated to "downplay," and possibly "deny," distress. Building on our prior work, in this study we hypothesize that high and low poles of maternal anxiety also will show similar patterns of altered contingencies. We explore low scores using nonlinear analyses of anxiety symptoms in relation to contingency. If our hypothesis is confirmed, report of very low symptoms may be problematic; however, we remain cautious: Without an independent distress measure, some participants at the low pole may be distressfree. 
Earlier, we hypothesized an "optimum midrange" model of contingency: Both low as well as high contingencies, in different communication modalities, may be associated with higher anxiety. Here, our examination of low as well as high anxiety scores constitutes another type of "optimum midrange" model of anxiety: Low as well as high poles of self-report anxiety may have similar altered contingencies, compared to mothers scoring midrange in anxiety. The former is a "conceptual" midrange model of contingency whereas the latter is a statistically nonlinear approach to anxiety.

\section{METHOD}

\section{Participants}

Recruitment-Within $24 \mathrm{hr}$ of delivering a healthy, full-term singleton infant without major complications, 152 primiparous mothers were recruited from an urban university hospital for a study of infant social development involving a 4-month lab visit. Participants were 18 years or older, married or living with a partner, with a home telephone. Mothers meeting criteria were consecutively approached. At 6 weeks, mothers were invited to participate by telephone. At 4 months, 119 mothers came to the lab, were videotaped with their infants, and then filled out anxiety-symptom scales. No mothers were in treatment or medicated. There were no differences in ethnicity, education, or infant gender between the 119 participants and the 152 recruited.

Demographic Description-Mothers were 53.0\% White, 28.0\% Hispanic, 17.5\% Black, $1.5 \%$ Asian; well-educated (3.8\% without high-school diploma, $8.3 \%$ without college, $28.8 \%$ some college, $59.1 \%$ college +$)$; mean age was $29(S D=6.5$, range $=18-45)$ years. Of 119 infants, 65 were male, and 54 were female.

\section{Procedure}

Scheduling of videotaping took into account infants' schedules. Mothers (seated opposite infants who were seated on a table) were instructed to play with their infants as they would at home, but without toys, for approximately $10 \mathrm{~min}$ (necessary to obtain vocal rhythm data for a separate report). A special-effects generator created a split-screen view from input of two synchronized cameras focused on mother and infant.

Measurement of anxiety symptoms-The STAI (Spielberger et al., 1983), a 40-item self-report scale, has items such as "nervous," "jittery," "high strung," "rattled," and "overexcited." State-Anxiety (SAS) evaluates how respondents feel "right now, at this moment." Trait-Anxiety (SAT) evaluates how participants "generally feel" with an identical set of items. SAS and SAT have been shown to be highly correlated. Test-retest coefficients for SAT range from .73 to .86 for college students, but are lower for SAS, as expected. Both forms have high internal consistency (a coefficients: SAS $=.87$, SAT $=.90$ ). We chose SAT, rather than SAS, to evaluate how mothers characterize themselves in general. Because SAT and the CES-D were correlated $(r=.65)$, a subsequent report will analyze both scales in the same analyses. Here, we report on SAT alone, more comparable to the literature. SAT was treated as a continuous variable in all data analyses. 
Behavioral coding-The first $2 \frac{1}{2}$ uninterrupted, continuous-play minutes of videotaped mother-infant play were coded on a 1-s time base (see Cohn \& Tronick, 1988; Field, Healy, Goldstein, \& Guthertz, 1990) by coders blind to anxiety status, using Tronick and Weinberg's (1990) timing rules. Codes were used to create ordinalized behavioral scales for data analysis (required by time-series techniques). Definitions of behavioral scales follow. Gaze: on-off partner's face; mother facial affect: mock surprise, smile 3, smile 2, smile 1, "oh" face, positive attention, neutral, "woe" face, negative face (frown, grimace, compressed lips); infant facial affect: high positive, low positive, interest/neutral, mild negative (frown, grimace), negative (pre-cry, cry-face); infant vocal affect: positive/neutral, none, fuss/ whimper, angry protest/cry; mother spatial orientation: upright, forward, loom; infant head orientation: en face, en face + head down, 30-to 60-degree avert, 30- to 60-degree avert + head down, 60- to 90-degree avert, arch; mother touch: affectionate, static, playful, none, caregiving, jiggle/bounce, oral, object-mediated, into the center of the body, rough, intrusive; infant touch: none, 1 , or $2+$ of the following behaviors within 1s: touch/suck own skin, touch mother, touch object (Hentel, Beebe, \& Jaffe, 2000). A dyadic code, chase and dodge, was defined as a minimum 2-s sequence in which infant averts head 30 degrees or more from vis-à-vis and mother moves her head or body in the direction of the infant's movement (Kushnick, 2002). We also constructed composite facial- visual "engagement" scales for mother and infant. Please refer to our Web site Appendices A, B, and C for further coding details (http://nyspi.org/Communication_Sciences/index.html).

Doctoral students in psychology independently coded mothers and infants. Reliability estimates (Cohen's $\kappa$ ) were computed on a per-dyad basis, for 30 randomly selected dyads (tested in three waves to prevent coder "drift"), for ordinalized scales (except mother touch, where $\kappa s$ were computed for the separate behaviors). Mean $\kappa s$ are presented for the 30 dyads (infants: gaze .80, face .78, touch .75, vocal affect .89, head orientation .71; mothers: gaze . 83 , face .68 , touch .90 ; spatial orientation .89 ; dyadic chase and dodge .89 ).

\section{Data Analysis}

Analyses of qualitative features of behavior-We first explored associations of maternal anxiety symptoms with qualitative features of behavior, tested as means of the ordinalized behavioral scales, as well as rates of specific "behavioral extremes." Although main effects of multilevel models could be interpreted for associations with means of behavioral scales, we chose to separately test for effects, without having controlled for the various other variables in our models, more comparable to the literature. For 4-month qualitative features of behaviors (scale means and rates of behavioral extremes), we used correlations and independent-samples $t$ tests.

Because the means of the behavioral scales have yielded little in our previous work, we moved to an exploration of "behavioral extremes" (see Beebe et al., 2010; Lyons-Ruth et al., 1999; Tomlinson, Cooper, \& Murray, 2005). For example, the mean of the ordinalized maternal touch scale includes the full range of maternal touch behaviors coded whereas the behavioral extreme of the low end of this scale, intrusive touch, identifies a specific, clinically meaningful behavior. The precise definitions of behaviors in question were critical 
in our previous work. In our behavioral extremes approach, we investigate whether associations with anxiety symptoms can be found in (a) the mere existence of a particular clinically relevant behavior (i.e., maternal intrusive touch), (b) the mean percentage of time per individual that it was used, or (c) its excessive use ( $\geq 20 \%$ time). Analyses were tailored to each behavior, as appropriate to the distributions (i.e., many were skewed).

Self- and interactive contingency-The second goal was to investigate associations of maternal anxiety symptoms with self- and interactive contingency. Modeling the complexity of real-time interactions remains difficult. Whereas traditional time-series approaches are considered state-of-the-art, the multilevel time-series models used in this study have many advantages. ${ }^{2}$ The SAS PROC MIXED program (Littell, Milliken, Stoup, \& Wolfinger, 1996; McArdle \& Bell, 2000; Singer, 1998) was used to estimate "random" (individual differences) and "fixed" (common model) effects on the pattern of self- and self-with-other behavior over $150 \mathrm{~s} .{ }^{3}$ The models examined six modality pairings, including one (on/off gaze) in which the dependent variable is dichotomous and therefore analyzed by SAS GLIMMIX (Cohen, Chen, Hamgiami, Gordon, \& McArdle, 2000; Goldstein, Healy, \& Rasbash, 1994; Littell et al., 1996; for details of statistical models, see Chen \& Cohen, 2006). These analyses use all $150 \mathrm{~s}$ coded from videotape for each individual. In these models, repeated observations on individuals are the basic random data, just as single individual variables are the basic units of analyses in cross-sectional data. Fixed effects, in contrast, indicate average effects over the full sample, so that it is possible to estimate the extent to which a single overall model accounts for the individual differences reflected in the random model.

Preliminary analyses estimated the number of seconds over which lagged effects were significant and their magnitude across the group (fixed model estimates). For each dependent variable, measures of prior self- or partner behavior, "lagged variables," were computed as a weighted average of the recent prior second. Typically, the prior $3 \mathrm{~s}$ sufficed to account for these lagged effects on the subsequent behavior. ${ }^{4}$ The estimated coefficient for the effects of these lagged variables on current behavior over the subsequent $147 \mathrm{~s}$ of interaction indicates the level of self- or interactive contingency: the larger the coefficient,

\footnotetext{
${ }^{2}$ To analyze interactive contingency, traditional time-series techniques first create two separate estimates per dyad (I $\left.\rightarrow \mathrm{M}, \mathrm{M} \rightarrow \mathrm{I}\right)$ of the magnitude of the effect of partner's prior behavior on the individual, controlling for the individual's prior behavior (autocorrelation). These estimates are then entered into regression equations to relate them to some other variable (e.g., anxiety symptoms); the error of the individual scores is lost. These ordinary least squares (OLS) estimates for each member of an interacting pair make the invalid assumption that the model predictors are fixed; that is, they represent investigator-selected, for example, maternal behaviors. This assumption ignores a source of error when the predictor is not selected or manipulated by the investigator whereas this source or error is taken into account in the multilevel time-series models, producing more accurate estimates. The multilevel models have more power, take into account error structures, and estimate individual effects with empirical Bayesian (maximum likelihood) techniques (rather than OLS), which take into account prior distributions. Because the prior probability of error is greatest for the extreme parameters, this method tends to pull in such extremes. Additional advantages of this approach are the simultaneous consideration of self- and partner behavior, the inclusion of control variables and their conditional effects as necessary, the examination of potential nonlinear relations in the same analyses, an increased information payload, and more appropriate statistical model assumptions. ${ }^{3} \mathrm{~A}$ "random effect" is the term used for identifying the differences in a variable (function, or association) among the study participants. These always include variation in the mean of the dependent variable across observations, and variation in the variance of the dependent variable across observations; they usually include variation in the linear change in the dependent variable over time. In our case, it includes between-dyad variation in the auto-regressive effect. A "fixed effect" is the average association across study units (in our case, dyads), just as it would be in an ordinary regression analysis. These average effects will account for some fraction of the random effects, just as in an ordinary regression analysis predictors account for some fraction of the variance in the dependent variable.
} 
the stronger the contingency. Each subsequent analysis included both self- and interactive contingency; thus, estimated coefficients of one form of contingency control for the other.

Tests of hypotheses use fixed rather than random effects. In preparation for tests of anxiety symptoms (SAT), a "basic model" of fixed (average) effects was produced for each behavioral dependent variable. The modeling process for predicting the time-varying ordinalized behavioral scale in question (e.g., mother facial affect) considered all demographic variables (maternal ethnicity, education, and age; infant gender), effects of lagged variables as described earlier, and all possible two-way interactions between control variables and self- and interactive contingency. Effects of lagged variables on current behavior represent the average contingency across the participants. Therefore, when testing for effects of SAT, any differences in the magnitude of these estimated coefficients in the fixed effects model reflect influences of SAT on self- and interactive contingency. Because our goal was an examination of the effects of SAT on contingency, we post on our Web site (http://nyspi.org/Communication_Sciences/index.html) Appendix D, the "basic model" tables of self- and interactive contingency (three for each of the six modality pairings, for a total of 18 tables). Prior basic across-group analyses (Beebe et al., 2008b) showed positive signs for self-contingency, and for interactive contingency with the exception of Pairing 6: mother spatial orientation-infant head orientation (mother negative sign, infant positive sign).

Variables in the "basic" multilevel model were added in these steps following the intercept of the dependent variable: (1) self- and partner lagged variables, (2) demographic variables, (3) conditional effects between demographic variables, (4) conditional effects of demographic variables with lagged self- and lagged partner behavior. Following each basic model, a conditional model examined the effect of SAT on each ordinalized behavioral scale and statistical interactions of SAT with self- and interactive contingency. ${ }^{5}$ Linear and quadratic conditional effects of SAT on self- and interactive contingency were assessed in the same models; linear and quadratic components each controlled for the other. Only those demographic variables from the basic models that also were associated with SAT could possibly confound these effects. Because none were associated with SAT, all demographic

\footnotetext{
${ }^{4}$ Preliminary analyses estimated the number of seconds over which lagged effects were statistically significant. For each dependent variable, measures of prior self- or partner behavior, termed "lagged variables," were computed as a weighted average of the recent prior second, based on these analyses. Typically, the prior $3 \mathrm{~s}$ sufficed to account for these lagged effects on the subsequent behavior. Across the modality pairings studied, mother was significant at two to three lags $(2-3 \mathrm{~s})$ for both self- and interactive contingency; evaluation of longer lags yielded nonsignificant results. Significant infant lags varied: for self-contingency, two lags (touch), three (facial affect, gaze), and four (vocal affect); for interactive contingency, six lags (mother gaze $\rightarrow$ infant gaze), five (mother facial affect $\rightarrow$ infant facial affect), and three (mother facial affect $\rightarrow$ infant vocal affect). Although some of these modality pairings showed lags longer than $3 \mathrm{~s}$, the amount of variance accounted for was very small for lags longer than $3 \mathrm{~s}$. Note that in the analyses, no more than three lags were used in any weighted mean lag, to maintain a consistent sample size.

${ }^{5}$ For the predicted value of mother behavior, the fixed effects equation for testing linear and nonlinear effects of Spielberger et al.'s (1983) Trait Anxiety (SAT) was
}

$$
M=M_{\text {lagged }}+I_{\text {lagged }}+\mathrm{SAT}+\mathrm{SAT}^{2}+M_{\text {lagged }}^{*} \mathrm{SAT}+M_{\text {lagged }}^{*} \mathrm{SAT}^{2}+I_{\text {lagged }}^{*} \mathrm{SAT}+I_{\text {lagged }}^{*} \mathrm{SAT}^{2}
$$

where $\mathrm{M}_{\text {lagged }}$ represents a weighted mean of mother's lagged behavior, $\mathrm{I}_{\text {lagged }}$ represents a weighted mean of infant's lagged behavior, SAT represents Spielberger Anxiety (Trait), and SAT ${ }^{2}$ represents Spielberger Anxiety(Trait) squared. Coefficients in the

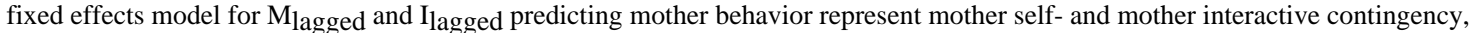
respectively (see Chen \& Cohen, 2006). 
variables were dropped from further consideration. Each model included a chi-square test of improvement of fit to the data. SAT was used as a continuous variable, centered by its mean. Standardized regression coefficients are presented in the tables. Type I error was set at $p<$. 05 for each model of the six modality pairings; all tests were two-tailed. With 119 dyads $\times$ $150 \mathrm{~s}=17,850 \mathrm{~s}$ per partner per communication modality, we had ample power to detect effects.

Linear components evaluated the conditional effects of higher (vs. lower) SAT scores on self- and interactive contingency; results were interpreted as characterizing higher SAT scores. Nonlinear components evaluated quadratic conditional effects of SAT; results were interpreted as characterizing movement toward the high and low poles, compared to dyads where mothers scored midrange in SAT. Where nonlinear analyses were significant, movement toward both high and low poles of SAT scores were associated with similar alternations in self- and interactive contingency (similar in direction, but not necessarily absolute amount).

Our interpretations occurred in two phases. Consistent with prior literature, we first evaluated findings associated with higher SAT scores. Here, we interpreted the linear as well as the higher portion of the nonlinear effects of SAT (right-hand side of graphed effects) on self- and interactive contingency. In the second phase, we examined nonlinear findings to evaluate whether movement away from the center toward high and low poles of SAT scores was associated with similar increases (or decreases) in self- and interactive contingency.

\section{RESULTS}

We first present descriptive information on Spielberger Trait Anxiety (SAT), followed by univariate tests of associations of SAT with ordinalized behavioral scales (facial affect, etc.). Effects of SAT on contingencies are then addressed. Consistent with the literature, we first present contingency findings associated with higher anxiety symptoms, whether linear or nonlinear. We then return to nonlinear equations to evaluate whether contingency findings of low-scoring SAT dyads look similar to those of high-scoring dyads.

\section{Description of Trait Anxiety Symptoms (SAT)}

The range of SAT scores at 4 months was 20 to 60 (possible 20-80). Mean SAT was 33.72 $(S D=9.05)$, close to norms of working adults $(M=33.75, S D=9.2)$. SAT was correlated with SAS, $r=.662 .{ }^{6}$ Maternal anxiety symptoms were not correlated with infant gender, maternal education, age, or ethnicity. A histogram of SAT (http://nyspi.org/ Communication_Sciences/index.html, Appendix E) shows a skewed distribution (skewness $=.72, S E=.22$ ). Representation at the high and low ends are adequate for our conclusions, but the high end is more differentiated (extending to $2 \frac{1}{2} S D$ above the mean) than is the low end (extending to $1 \frac{1}{2} S D$ below the mean). The distribution mean is approximately 34 , the

\footnotetext{
${ }^{6}$ The SAS mean (32.1), $S D$ (7.87), and range (20-60) were close to norms of working adults $(M=35.5, S D=10.5)$. SAS and CES-D scores were correlated, $r=.50$; SAT and CES-D scores were correlated, $r=.65$.
} 
$M d n$ is 32 , and the mode is 26 to 28 . Using an interquartile range, a score of 27 and below defines the low $25 \%$ of participants; $40+$ defines the upper $25 \%$. These considerations will make our interpretation of the low anxiety-symptom pole in the nonlinear analyses more conservative. In a community sample of 1,076 women postpartum, mothers scoring higher than $1 S D$ above the mean on SAT (43+) were at greater risk for anxiety-related disorders (Gilboa, Granat, Feldman, Kvint, \& Merlov, 2004). Our upper quartile is in this range.

\section{Are Maternal Anxiety Symptoms Associated With Qualitative Behavioral Features?}

Appendix F (http://nyspi.org/Communication_Sciences/index.html) presents the results of testing associations of anxiety symptoms with means of the behavioral scales (Appendix F1) and rates of behavioral extremes (Appendix F2, tested as percent time, except where indicated as "ever"). Regarding the means of the behavioral scales, there were no significant associations of maternal anxiety with infant means of behavioral scales [gaze, facial affect, vocal affect, engagement, touch and head orientation (http://nyspi.org/ Communication_Sciences/index.html, see Appendix A for definitions of scales)]. There was one (of five possible) significant association of maternal anxiety with maternal means of behavioral scales [gaze (tested as \%time), facial affect, engagement, touch, and spatial orientation]. Mothers with higher (vs. lower) anxiety symptoms gazed at infants a greater percent of the time, $r=.214, p<.05$.

The testing of behavioral extremes is exploratory because there is no literature on which to base hypotheses; however, our previous analysis of associations of mother and infant selfand interactive contingency with infant attachment in this dataset did yield rich findings using the approach of behavioral extremes (Beebe et al., 2010). The following infant behavioral "extremes" were tested (as \%time, except where indicated as "ever") for associations with higher anxiety: (a) negative facial affect, (b) negative vocal affect, (c) distress (facial or vocal), (d) discrepant affect (facial/vocal), (e) no touch, (f) touch own skin, (g) touch mother, (h) touch object, (i) head avert or arch, (j) avert (60-90 degrees) (ever), (k) arch (ever), (l) engagement-positive affect/gaze off, (m) engagement-look angled for escape, and (n) engagement-negative affect/gaze on. None showed significant associations with anxiety.

The following maternal behavioral extremes were tested for associations with higher anxiety: (a) negative facial affect, (b) positive facial affect (smile 2, smile 3, mock surprise), (c) interruptive touch, (d) intrusive touch, (e) loom, (f) mother positive/infant distressed, (g) woe face, and (h) chase + dodge (ever). No analyses were significant. A nonsignificant trend $(p=.08)$ toward more negative maternal facial expressions with anxiety was evident, consistent with our hypothesis.

Maternal gaze was significant in one of five behavioral means tested (20\% of analyses); however, once measures of means and behavioral extremes are combined, many maternal tests were run. This maternal gaze finding will need replication. 


\section{Are Higher Maternal Anxiety Symptoms Associated With Altered Contingencies?}

In this section, we present contingency findings associated with higher SAT scores, whether linear or nonlinear. Using multilevel time-series analysis, we report the effects of SAT on estimates ( $\beta$ ) of self- and interactive contingency. Nonlinear effects refer to the higher portion of the effects (the right-hand portion of the graphed effects). For example, in linear findings, mothers with higher maternal anxiety symptoms may show altered contingency (higher or lower) compared to mothers scoring lower in symptoms; in nonlinear findings, mothers with higher symptoms may show altered contingency (higher or lower) compared to mothers scoring midrange in symptoms. Next, both sets of effects are summarized as contingency patterns associated with higher maternal anxiety symptoms. These linear and nonlinear estimates are presented in Table 1 and are illustrated in Figure 1. Significant effects in Table 1 indicate that when mothers had elevated anxiety symptoms (by $1 S D$ from the mean), contingency is lowered (negative sign), or heightened (positive sign).

In Figure 1, arrows which curve from infant to mother represent maternal interactive contingency (vice versa for infant); arrows which curve back into one partner's behavior represent self-contingency. The notation I $\rightarrow \mathrm{M}$ for interactive contingency indicates that lagged infant behavior in the prior few seconds predicts maternal behavior in the current moment: Mother contingently coordinates with infant (vice versa: $\mathrm{M} \rightarrow \mathrm{I}$ ). Broken arrows represent findings in which higher anxiety symptoms generated lowered contingency values; unbroken arrows represent findings in which higher anxiety symptoms generated heightened contingency values (compared to lower anxiety symptoms for linear equations; compared to midrange anxiety symptoms for nonlinear equations). The absence of arrows represents no effects of anxiety symptoms.

Brackets in margins of Figure 1 demarcate four domains: attention (Pairing 1), affect (Pairings 2, 3), mother touch in relation to infant behavior (Pairings 4, 5), and orientation (Pairing 6). The notation $L$ indicates linear effects, and $N L$ denotes nonlinear effects. Where both $\mathrm{L}$ and NL effects are significant, the $\mathrm{L}$ relation characterizes more of the group than does the NL.

- Pairing 1: Infant Gaze-Mother Gaze: Self-contingency: no findings; Interactive contingency: no findings.

- Pairing 2: Infant Facial Affect-Mother Facial Affect: Self-contingency: no findings; Interactive contingency: Mothers with higher (vs. midrange) anxiety symptoms lowered their facial coordination with infant facial affect, but infants of more (vs. less) symptomatic mothers showed the opposite pattern of heightened facial coordination with maternal facial affect. Table 1 shows that when mothers had elevated anxiety symptoms (by $1 S D$ above the mean), maternal interactive contingency was lowered by -.014 , and infant interactive contingency was heightened by .032 .

- Pairing 3: Infant Vocal Affect-Mother Facial Affect: Self-contingency: With higher (vs. midrange) maternal anxiety symptoms, infant vocal affect self-contingency was lowered; Interactive contingency: Mothers with higher (vs. midrange) anxiety 
symptoms lowered facial coordination with infant vocal affect, and their infants likewise lowered vocal affect coordination with mother facial affect.

- Pairing 4: Infant Vocal Affect-Mother Touch: Self-contingency: With higher maternal anxiety symptoms, infant vocal affect self-contingency was both (a) heightened [compared to infants of more (vs. less) symptomatic mothers] and (b) lowered (compared to infants of midrange anxiety scoring mothers). With higher anxiety symptoms, maternal touch self-contingency was both (a) heightened (compared to mothers scoring lower in symptoms) and (b) lowered (compared to mothers scoring midrange); Interactive contingency: Mothers with higher (vs. midrange) anxiety symptoms heightened their touch coordination with infant vocal affect. Infants of more symptomatic mothers (a) lowered their vocal affect coordination with maternal facial affect (compared to infants of lower symptom mothers) and (b) heightened their vocal affect coordination with maternal facial affect (compared to infants of midrange symptom scoring mothers).

- Pairing 5: Infant Touch-Mother Touch: Self-contingency: With higher (vs. midrange) maternal anxiety symptoms, infant touch self-contingency was lowered, and with higher (vs. lower) maternal symptoms, maternal touch self-contingency was heightened; Interactive contingency: no findings.

- Pairing 6: Infant Head Orientation-Mother Spatial Orientation: Self-contingency: With higher (vs. midrange) maternal anxiety symptoms, self-contingency of both infant head orientation and maternal spatial orientation were lowered; Interactive contingency: no findings.

In summary, of equations run (48 linear and nonlinear), 33\% (16 of 48) were significant, a nonrandom pattern of findings. Of infant equations run, 37.5\% (9 of 24) were significant; of mother equations run, $29.2 \%$ ( 7 of 24). Of significant equations, self-contingency accounted for $56.25 \%$.

\section{Are Alterations in Contingency Associated With the Low Pole of Anxiety Symptom Scores Similar to Those Associated With the High Pole? Nonlinear Analyses}

The previous section described findings of dyads in which mothers endorsed higher anxiety symptoms. We now return to the nonlinear analyses of Table 1, graphed in Web site Appendix G (http://nyspi.org/Communication_Sciences/index.html), to interpret findings at the low anxiety symptom pole. Where significant, nonlinear analyses show that alterations in contingencies associated with movement toward the low pole are similar (in direction, but not necessarily in absolute amount) to those associated with the high pole (vs. dyads with midrange scores). Of the significant equations, 69\% (11 of 16) were nonlinear.

- Pairing 1: Infant Gaze-Mother Gaze: Self-contingency: no nonlinear finding; Interactive contingency: no nonlinear finding.

- Pairing 2: Infant Facial Affect-Mother Facial Affect: Self-contingency: no nonlinear finding; Interactive contingency: As maternal anxiety symptoms were elevated (by $1 S D$ from the mean) toward the high pole, and lowered (by $1 S D$ ) toward the low pole, mothers showed similar decreases in facial coordination with 
infant facial affect (vs. mothers scoring midrange in anxiety symptoms). This effect is more pronounced at the high symptom end (http://nyspi.org/ Communication_Sciences/index.html, Appendix G).

- Pairing 3: Infant Vocal Affect-Mother Facial Affect: Self-contingency: As maternal anxiety symptoms moved toward high and low poles, infants showed similar decreased vocal affect self-contingency (vs. infants whose mothers scored midrange in symptoms), more pronounced at the high pole; Interactive contingency: As maternal anxiety symptoms moved toward the high and low poles, (a) mothers showed decreased facial coordination with infant vocal affect, and (b) infants showed decreased vocal affect coordination with maternal facial affect. These effects are more pronounced at the high pole.

- Pairing 4: Infant Vocal Affect-Mother Touch: Self-contingency: Compared to dyads in which mothers scored midrange in anxiety symptoms, as symptoms moved toward high and low poles, (a) infants showed decreased vocal affect selfcontingency, an effect more pronounced at the high pole; and (b) mothers showed very subtle decreased touch self-contingency; Interactive contingency: Compared to dyads in which mothers scored midrange in anxiety symptoms, as symptoms moved toward high and low poles, (a) infants showed increased vocal affect coordination with maternal touch; and (b) mothers showed increased touch coordination with infant vocal affect.

- Pairing 5: Infant Touch-Mother Touch: Self-contingency: As maternal anxiety symptoms moved toward high and low poles, infants showed subtle decreases in touch self-contingency (vs. infants whose mothers scored midrange in symptoms). Because the effect is so subtle at the low pole, this effect is interpreted at the high pole only (http://nyspi.org/Communication_Sciences/index.html, Appendix G); Interactive contingency: no nonlinear finding.

- Pairing 6: Infant Head Orientation-Mother Spatial Orientation: Self-contingency: Compared to dyads in which mothers scored midrange in anxiety symptoms, as symptoms moved toward high and low poles, (a) infants showed very subtle decreases in head orientation self-contingency, and (b) mothers showed decreases in spatial orientation self-contingency. Because the effect is so subtle at the low pole, this effect on maternal self-contingency is interpreted at the high pole only; as symptoms increase, the decrease in self-contingency accelerates; Interactive contingency: no nonlinear finding.

\section{DISCUSSION}

We investigated the effects of maternal self-reported trait anxiety symptoms on motherinfant face-to-face communication at 4 months. After noting descriptive information, we describe the qualitative features of behavior associated with maternal anxiety symptoms. The meaning of heightened and lowered contingencies is then addressed, as is our hypothesis that distress biases the communication system toward both heightened self- and interactive contingencies (in some modalities) and lowered self- and interactive contingencies (in others). We then describe the picture of higher maternal anxiety symptoms 
in relation to contingencies across the modalities of attention, affect, touch, and spatial orientation. Our question of whether contingency patterns of dyads at the low pole of anxiety symptoms look similar to those at the high pole is addressed next. We then interpret our self- and interactive contingency findings as forms of self- and interactive regulation. Finally, limitations of the study, and implications for early intervention, are noted.

\section{Descriptive Information}

In our low-risk community group, the incidence of anxiety symptoms was no different from that of the general population. Associations between anxiety symptoms and infant gender, and maternal age, education, and ethnicity, were absent.

\section{Qualitative Features of Behavior Associated With Maternal Anxiety Symptoms}

Only one qualitative feature of behavior was identified: mothers with higher (vs. lower) anxiety-related symptoms spent a greater percentage of time looking at their infants' faces. A nonsignificant trend $(p=.08)$ toward more negative maternal facial expressions is consistent with clinical observation in this group as well as with our hypothesis, but would require replication. Otherwise, higher (vs. lower) symptom dyads did not differ in qualitative behavioral features (see http://nyspi.org/Communication_Sciences/index.html Appendices F1 \& F2). The absence of qualitative features may reflect the low-risk nature of this community sample.

\section{Hypotheses Regarding Interactive and Self- Contingency}

Differences were found in self- and interactive contingency rather than in behavioral qualities, a striking finding (also see Beebe et al., 2007). Contingency addresses the process of relating over time whereas behavioral qualities address specific rates of behaviors, taken out of time. Regarding interactive contingency, findings were consistent with our hypothesis that across the system of both partners and all communication modalities, maternal anxiety symptoms bias the system toward both heightened values (in some modalities) and lowered values (in others). Consistent with our prediction, mothers with anxiety-related symptoms lowered their interactive contingencies in affective modalities: They lowered facial affect coordination with infant facial and vocal affect. We anticipated that these mothers would show heightened interactive contingencies in gaze; instead, we found that mothers spent more time gazing at their infants. As anticipated, we found heightened maternal touch coordination, and infants of mothers with anxiety-related symptoms heightened their facial affect coordination with maternal facial affect. However, not consistent with our prediction, infants lowered their vocal affect coordination with maternal facial affect. We did not substantiate our prediction that infants would show lowered contingency with mothers in modalities other than affect. Instead, we found a complex pattern involving infant vocal affect and maternal touch (discussed later).

Regarding self-contingency, we hypothesized both lowered and heightened values associated with anxiety symptoms; instead, infant self-contingency was lowered in four (of five) significant equations. In the only exception, infants heightened self-contingency of vocal affect paired with maternal touch. Thus, infant activity rhythms of facial and vocal affect, touch, and head orientation were largely "destabilized" when mothers reported 
anxiety-related symptoms. Lowered self-contingency indicates a lowered ability to anticipate one's own ongoing behavioral stream, so that one knows less what to expect of oneself. The cues by which one knows oneself are less predictable, yielding a decreased sense of coherence over time. In our prior work, lowered infant self-contingency was evident with maternal depression, self-criticism, and dependency (Beebe et al., 2007; Beebe et al., 2008a).

Consistent with our hypothesis, mothers with anxiety-related symptoms showed selfcontingency patterns that were both heightened [mother touch paired with infant touch and vocal affect $(\mathrm{L})$ ], and lowered [spatial orientation, and mother touch paired with infant vocal affect (NL), consistent with an optimum midrange model of contingency. Maternal dysregulated inner state can thus manifest in self-contingencies that are both too high and too low. We now turn to a detailed discussion of findings.

\section{The Picture of Higher Maternal Anxiety Symptoms}

Gaze-Although we conjectured that mothers with anxiety symptoms would show heightened gaze contingency, instead they showed heightened time looking at their infants' faces. This finding may reflect maternal efforts to monitor "what is happening," out of fear that the contact "will not work," or in an effort to see if "everything is okay." It is a vigilance consistent with an overly aroused maternal state. Gaze vigilance toward the face of the partner is consistent with the literature on anxiety documenting that attentional vigilance for emotional faces is higher in anxious individuals (Bradley \& Mogg, 1999; Fox, Russo, \& Dutton, 2002).

Facial affect-Consistent with our prediction (also see Kaitz \& Maytal, 2005), mothers with anxiety symptoms lowered their facial coordination with infant facial affect, an affective "withdrawal." In contrast, their infants showed the opposite, a heightened facial coordination with maternal facial affect, indicating an affective "approach" or "vigilance." This finding is consistent with our prediction, and with de Rosnay et al.'s (2006) suggestion that infants of symptomatic mothers may be overly sensitive to maternal affective communication. This infant "facial approach"-maternal "facial withdrawal" is a pattern of interpersonal conflict. Mothers may need to withdraw from infant facial affect to protect their own overly aroused inner state, but infants may need to be facially vigilant in a compensatory effort to monitor and "stay with" a mother who is affectively withdrawn.

Maternal gaze/face discordance-It is striking that mothers with anxiety symptoms showed more time gazing at infants' faces, yet lowered their facial coordination with infant facial affect: a form of intermodal discordance likely to be confusing to infants. To illustrate, although these mothers looked more at infant faces, when infants showed happy faces, these mothers were less likely to show delight; when infants showed distressed faces, these mothers were less likely to show facial empathy. Thus, these mothers vigilantly monitored infants visually, but they did not emotionally respond empathically to infants. This maternal facial-emotional withdrawal is construed as a "violation" of a universal expectation that one's emotional state will be acknowledged through a correlated change in the partner (Tronick, 1989), yielding a concordant state. Vigilant visual monitoring, without empathic 
emotional response, suggests that mothers may be "looking through" the infants' faces, as if the infant is not "seen" or experienced, consistent with Kaitz and Maytal's (2005) description that symptomatic mothers seem self-absorbed or detached. This maternal pattern may be a self-protective effort to dampen arousal and partially disengage, to avoid further distress.

Maternal facial affect-infant vocal affect-Mothers with anxiety symptoms and their infants both lowered their coordination in this pattern, a mutual affective withdrawal likely sensed by each partner. Infants also showed lowered self-contingency of vocal affect, a selfdestabilization. The lowered infant self-predictability may be more difficult to "read" and thus may contribute to lowered maternal coordination. Integrating the aforementioned finding, these mothers lowered their facial coordination with both infant facial and vocal affect-a striking maternal emotional withdrawal. Lowered maternal facial coordination decreases infant interactive "efficacy:" It is harder for infants to anticipate consequences of their facial/vocal affect on mothers' facial affect.

Infant discordant coordination with mother's face-Integrating the two infant facial and vocal findings noted earlier, infants heightened their facial affect coordination (vigilance), but dampened their vocal affect coordination (withdrawal), with mother's face. Infants may become facially vigilant to maternal facial affect to resolve the conflicting maternal signals of heightened gaze but dampened facial coordination or to compensate for maternal emotional withdrawal and their own lowered efficacy. Yet, infants dampened their vocal affect coordination with maternal facial affect, an inhibition or withdrawal. The two findings together generate a remarkable infant intrapersonal intermodal discordance, or conflict. The combination of maternal gaze/facial affect discordance and infant facial/vocal affect discordance can be seen as a mutual perplexity, a mutual affective ambivalence, ${ }^{7}$ confusing to both partners. This finding elucidates with unique specificity how mothers and infants together may construct communication disturbances.

Maternal touch-infant vocal affect-In our prior across-group analysis of these mothers and infants (Beebe et al., 2008b), we documented that mothers coordinate their touch with infant vocal affect. As infant vocal affect becomes more positive, maternal touch patterns are more affectionate, and vice versa. The "average" infant across the group, however, did not reciprocally coordinate vocal affect with maternal touch.

Here, we document that with increasing anxiety symptoms, as infant vocal affect becomes more positive, mothers are even more likely to touch with affectionate patterns; vice versa, as infant vocal affect inevitably becomes more negative, mothers are even more likely to touch with less affectionate patterns (see Figure 1). It is striking that mothers dampened their facial coordination with infant vocal affect (as noted earlier), but heightened their touch coordination with infant vocal affect, an intermodal discordance.

\footnotetext{
${ }^{7}$ We use the term ambivalence to refer to a procedural form of ambivalence, in which action sequences are simultaneously organized in opposite directions, to distinguish it from a symbolic representational form of ambivalence.
} 
We suggest that this higher maternal touch coordination reflects a compensatory maternal effort to make contact, consistent with reports that maternal touch "repairs" the effects of the still-face experiment on the infant (Stack \& Muir, 1992). It also may reflect a tendency toward "doing" rather than "feeling," in an attempt to ward off helplessness (Chorpita \& Barlow, 1998). Most mothers with anxiety symptoms also heightened their touch selfcontingency, a self-stabilization. Thus, mothers with anxiety symptoms have a more selfstable and more highly coordinated touch pattern. This touch pattern may be more "readable" by the infant, and may indicate a maternal compensatory effort to "repair" the interaction, which is disrupted in the affective modalities, as noted earlier. Nevertheless, this "repair" falls apart when infants inevitably become vocally distressed.

It is striking that infants of mothers with anxiety symptoms showed coordination with maternal touch whereas the "average" infant across the group did not (Beebe et al., 2008b). Moreover, most infants lowered their coordination with maternal touch, a withdrawal. This is a conflictual interactive contingency pattern of maternal "approach:" infant "withdrawal." Thus, most infants withdrew from mothers in their compensatory touch coordination efforts. Most infants also heightened their self-contingency of vocal affect, a self-stabilization.

However, at the high end of symptom scores, in this mother touch-infant vocal affect pairing, infants showed a heightened coordination, a vigilance, and a lowered selfcontingency, a destabilization. Thus, at the high end of scores, infants and mothers generated a mutual interactive vigilance. We interpret mutual vigilance as a dyadic attempt to create more predictability in the context of stress (Jaffe et al., 2001), a mutual compensatory effort.

Mother spatial orientation-infant head orientation-Although there were no interactive contingency findings in this pattern, both mothers and infants showed lowered self-contingency, a mutual orientational destabilization. Thus, as mothers with anxiety symptoms moved among spatial orientations of sitting upright, to leaning forward, to looming in, they were less predictable. This lowered predictability disturbs the "spatial frame" of the face-to-face encounter, a background sense of spatial structure that mothers usually provide. It also generates infant difficulty in decoding and predicting maternal behavior, decreasing infant sense of agency. Similarly, as their infants oriented their heads in a continuum from enface toward arch, they were less predictable, generating less clear signals to mothers as to whether they were staying enface, "going out" toward arch, or "coming back in."

In summary, mothers with anxiety-related symptoms vigilantly monitored infants visually, but withdrew from contingently coordinating with infant affective ups and downs, and thus did not emotionally respond empathically to infants. Infants were intently looked at, but not emotionally responded to, as if mothers were "looking through" them. This picture fits descriptions of anxious mothers in the literature as overaroused and fearful, leading to vigilance, but simultaneously emotionally withdrawn and less sensitive, dealing with their fear and overarousal through emotional distancing (Barlow, 1991; Kaitz \& Maytal, 2005; Feldman et al., 1997; Nicol-Harper et al., 2007; Warren et al., 2003). For their part, infants heightened facial affect coordination (vigilance), but dampened vocal affect coordination (withdrawal), with mother's face, a pattern of conflict regarding mother's face. We interpret 
the combination of maternal gaze/facial affect discordance and infant facial/vocal affect discordance as a mutual perplexity, a mutual affective ambivalence. In the context of these affect and visual attention-regulation difficulties, mothers heightened their contingent touch coordination with infant vocal affect, perhaps a compensatory effort, but infants mostly withdrew from coordinating with maternal touch. Finally, both mothers and infants exhibited a mutual orientational destabilization, generating difficulty in each partner in predicting what the other will do next, in spatial orientation.

We suggest that these maternal patterns of emotional withdrawal, attentional/facial discordance, and maternal discordant coordination with infant vocal affect are highly unusual. Moreover, these patterns introduce a "primary disturbance" similar to, but not as extreme as, the "still-face" experiment (Tronick, 1989). The remarkable infant conflicting responses to maternal facial affect is reminiscent of Weinberg and Tronick's (1996) description of infant ambivalence during the reunion episode following the still-face. In the reunion episode (compared to baseline play), infants show even more joyful faces, but they also continue the increased incidence of sadness and anger shown during the still-face. Like Weinberg and Tronick (1996), our findings also document remarkable differentiation, specificity, and discordance in infant intermodal emotional organization, which can be described as infants in conflict.

\section{Evaluating Low and High Poles of Maternal Anxiety Symptoms}

Because self-report scales are vulnerable to denial (Shedler et al., 1993), we hypothesized that very low anxiety-symptom scores may be associated with communication difficulties similar to those of very high scores. Testing this notion with nonlinear analyses, $69 \%$ of findings were nonlinear. Where mothers endorsed either high or low symptom poles, dyads showed roughly similar patterns of altered contingency, compared to dyads in which mothers had midrange anxiety-symptom scores. Next, we note only those patterns with significant nonlinear findings.

Regarding maternal interactive contingency, mothers at both high and low poles of anxiety symptoms (more pronounced at the high pole) dampened facial coordination with infant facial/vocal affect shifts, but heightened touch coordination with infant vocal affect. Regarding infant interactive contingency, infants of mothers at both high and low poles lowered vocal affect coordination with maternal facial affect (more pronounced at the high pole), but heightened vocal affect coordination with maternal touch. Regarding maternal self-contingency, mothers at both the high and low poles similarly showed very subtle decreases in touch self-contingency, and decreases in spatial orientation self-contingency (at the high pole only). Regarding infant self-contingency, infants of mothers at both high and low poles showed decreases in vocal affect self-contingency (more pronounced at the high pole), subtle decreases in touch self-contingency (at the high pole only), and subtle decreases in head-orientation self-contingency.

Although we are intrigued by these nonlinear findings indicating difficulty at the very low pole of anxiety symptoms, we remain cautious. Some mothers reporting very few or no symptoms may indeed be less vulnerable whereas others may be using denial. Long-term consequences for infant development in dyads in which mothers have very low distress 
scores are unclear (Lyons-Ruth et al., 1986). Because of the clinical significance of maternal denial of distress, and disagreement as to its existence and consequences, further research is needed (Pickens \& Field, 1993; Tronick et al., 1997; Weinstein \& Kahn, 1955).

\section{Implications of Contingency Findings for the Concept of "Regulation"}

The concept of regulation is defined differently in varying research traditions (Campos, Frankel, \& Camras, 2004; Cole, Martin, \& Dennis, 2004; Davidson, Jackson, \& Kalin, 2000). Our contingency measures, assessing predictability of behavior over time, qualify as one definition of regulation (Cohn \& Tronick, 1988; Jaffe et al., 2001). Comparing Cole et al.'s (2004) review of definitions of regulation, our approach fits their "analysis of temporal relations" using time-based methods, illustrated with the work of Cohn and Tronick (1988): "well-suited to inferring that each person's behavior regulates that of the partner" (Cole et al., 2004, p. 324). Thus, we construe our self- and interactive contingency findings as forms of self- and interactive regulation and as relevant to that literature (see Beebe \& Lachmann, 2002; Cohn \& Tronick, 1988; Sander, 1977; Stern, 1985; Tronick, 1989). Although this approach is familiar for interactive regulation, it is less so for self-regulation (but see Downey \& Coyne, 1990; Thomas \& Malone, 1979; Warner, 1992).

\section{Limitations of the Study}

Our highly educated sample is not representative of the general population, although the ethnic diversity of the sample is typical of an urban hospital setting. Nevertheless, the level of self-reported anxiety symptoms was the same as in the general population. As Campbell and Cohn (1991) argued, even in the absence of meeting formal diagnostic criteria, mothers who report distress may communicate it to their infants. Furthermore, we consider a selfreport instrument more appropriate to our community sample than a clinical one. Motherinfant communication difficulties have been identified regardless of whether maternal distress is measured by a clinician-based diagnosis or by self-report (Gitlin \& Pasnau, 1989; Murray \& Cooper, 1997). An important limitation is the difficulty of disentangling the effects of anxiety symptoms with those of depressive symptoms, which are highly correlated, as would be expected. We address this limitation in a subsequent report. However, our results are applicable to the common clinical situation of comorbid anxious and depressive symptoms. Moreover, because so little is known about mother-infant communication associated with anxiety-related symptoms, the first appropriate step is our examination of the widely used self-report scale, the STAI, prior to disentangling anxiety and depression symptoms.

Maternal gaze was significant in one of five behavioral means tested (20\% of analyses); however, once measures of means and behavioral extremes were combined, many maternal tests of behavioral qualities were run. Thus, this finding of heightened maternal gaze with anxiety will need replication. The finding is strengthened by the fact that gaze vigilance is consistent with the literature on anxiety as well as our hypothesis that mothers would more tightly coordinate their gaze patterns with those of their infants.

Without prenatal assessment of maternal anxiety-related symptoms, we may attribute too much influence to postnatal factors (O'Connor et al., 2002). We also do not know whether 
infants of anxious mothers may contribute their own organismic difficulties. Although the infant sample was chosen for physiological integrity, the fetal heart rate of anxious mothers is dysregulated (Monk, Myers, Sloan, Ellman, \& Fifer, 2003). However, regardless of underlying etiology, mother-infant face-to-face interaction is a final common pathway (Tronick, 1989) in which disturbances of communication are played out, and into which clinicians may intervene.

\section{Clinical Implications}

In our method of brief clinical interventions with mothers through therapeutic viewing of videotapes of face-to-face interaction, we sensitize mothers to nonverbal communication to illustrate how each partner may affect the other as well as regulate oneself (Beebe, 2003, 2005; Cohen \& Beebe, 2002; Stern, 1995). Using the mother's own concerns as an entry point, we inquire what the mother thinks the baby is feeling and what she herself might be feeling, frequently pointing out successful moments. The mother's associations are explored, enhancing the mother's ability to perceive and reflect on the infant's "state of mind" as well as her own (see Fonagy, Gergely, Jurist, \& Target, 2002). If replicated, our findings on maternal anxiety symptoms and mother and infant contingencies can enhance the specificity of interventions.

Using therapeutic viewing of videotape, vigilant maternal looking at the infant's face can be explored as mother's efforts to monitor "what is happening" or her worry that the engagement "will not work." The mother's own sense of safety, and her "safety" with her baby, can be investigated. Mothers can be helped to pay more attention to the infant's subtle facial and vocal affect fluctuations and to explore why it might be hard for the mother to "go with" or track them. For example, one mother felt that her baby's face was hard to read, and it reminded her of her own mother's face: She never knew "where she was at" with her mother, or with her baby (Beebe, 2005). Infant vigilant facial coordination with mother's facial shifts can be demonstrated, and the mother can be encouraged to imagine what her baby sees in her face and what the baby might be looking for as a way to increase her empathy for the baby's need for the mother's facial coordination.

The ways in which infants of mothers with very high anxiety symptoms are highly responsive to maternal touch patterns through vocal affect can be demonstrated and interpreted as the infant's way of "finding" the mother, similar to the infant's careful facial attention to mother's face. Mothers can be shown how they reciprocally pay close attention to the infant's vocal affect through their own touch, encouraging maternal ability to attend to subtle infant cues.

Using the findings of self-contingency, mothers can be helped to appreciate the importance of their own - and their infant's—stability and predictability, which can be facilitated through educational, interpretive, and imaging strategies.

In summary, dyads with higher maternal anxiety-related symptoms showed both heightened (vigilant) and lowered (withdrawn) patterns of interactive contingency, as a function of communication modality, consistent with an optimum midrange model of interactive contingency. Infant self-contingency was consistently lowered; maternal self-contingency 
was both heightened and lowered, as a function of communication modality. The picture of higher maternal anxiety symptoms was characterized by intermodal discordances, forms of procedurally organized intrapersonal and interpersonal conflict.

\section{ACKNOWLEDGMENTS}

This work was funded by NIMH RO1 MH 56130, the Koehler Foundation, the American Psychoanalytic Association, the Edward Aldwell Fund, and the Los Angeles Fund for Infant Research and Psychoanalysis. We thank George Downing, Katherine Weinberg, Estelle Shane, Frank Lachmann, Marvin Hurvich, Lin Reicher, Doris Silverman, Anni Bergman, Max Malitzky, and the Monday afternoon study group. We thank our students who filmed the mothers and infants: Lisa Marquette, Caroline Flaster, Patricia Goodman, Jill Putterman, Limor Kaufman-Balamuth, Elizabeth Helbraun, and Shanee Stepakoff. We thank our students who coded the motherinfant videotaped data: Lisa Marquette, Elizabeth Helbraun, Michaela Hager-Budny, Shanee Stepakoff, Jane Roth, Donna Demetri-Friedman, Sandra Triggs-Kano, Greg Kushnick, Helen Demetriades, Allyson Hentel, Tammy Kaminer, and Lauren Ellman. We thank our lab assistants Alla Chavarga, Nidhi Parashar, Julia Reuben, Brianna Hailey, Priscilla Caldwell, Robbie Ross, Kate Lieberman, Alina Pavlakos, Sarah Temech, Jennifer Lyne, Elizabeth White, Yana Kuchirko, Greer Raggio, Hope Igleheart, Jessica Latack, and Sara Schilling. We thank our former research assistants who contributed to this work: Helen Weng, Adrienne Lapidous, Kara Levin, Adrianne Lange, Sarah Miller, Matthew Kirkpatrick, Christy Meyer, Lauren Cooper, Michael Klein, Annee Ackerman, Sandy Seal, Sam Marcus, Iskra Smiljanic, Victoria Garel, Leslie Michael, and Jessica Silverman. We thank our students and colleagues Sarah Hahn-Burke, Nancy Freeman, Alan Phelan, Danielle Phelan, Paulette Landesman, Tina Lupi, Michael Ritter, Jillian Miller, Glenn Bromley, Robert Gallaghan, Naomi Cohen, Kristen Kelly, Irena Milentevic, Marina Koulomzin, and Jerilyn Kronen. We thank John Burke and William Hohauser of ESPY TV. We thank our anonymous reviewer, who made the work far better.

\section{REFERENCES}

Austin M. Antenatal screening and early intervention for "perinatal" distress, depression and anxiety: Where to go from here? Archives of Women's Mental Health. 2004; 7:1-6.

Badalamenti A, Langs R. An empirical investigation of human dyadic systems in the time and frequency domains. Behavioral Science. 1990; 36:100-114. [PubMed: 2049055]

Bahrick L, Hernandez-Reif M, Flom R. The development of infant learning about specific face-voice relations. Developmental Psychology. 2005; 4:541-552. [PubMed: 15910161]

Barlow DH. Disorders of emotion. Psychological Inquiry. 1991; 2(1):58-71.

Barnett B, Parker G. Possible determinants, correlates, and consequences of high levels of anxiety in primiparous mothers. Psychological Medicine. 1986; 16:177-185. [PubMed: 3961043]

Beebe B. Brief mother-infant treatment using psychoanalytically informed video microanalysis. Journal of Infant Mental Health. 2003; 24:24-52.

Beebe B. Mother-infant research informs mother-infant treatment. Psychoanalytic Study of the Child. 2005; 60:7-46. [PubMed: 16649674]

Beebe B, Jaffe J, Buck K, Chen H, Cohen P, Blatt S, et al. Six-week postpartum maternal self-criticism and dependency and 4-month mother-infant self- and interactive contingencies. Developmental Psychology. 2007; 43:1360-1376. [PubMed: 18020817]

Beebe B, Jaffe J, Buck K, Chen H, Cohen P, Feldstein S, Andrews H. Six-week post-partum maternal depressive symptoms and 4-month mother-infant self- and interactive contingency. Infant Mental Health Journal. 2008a; 29(5):442-471.

Beebe, B.; Jaffe, J.; Buck, K.; Chen, H.; Cohen, P.; Feldstein, S.; Andrews, H. Mother-infant self- and interactive contingency across modalities: A systems view. New York State Psychiatric Institute; 2008b. Unpublished manuscript

Beebe B, Jaffe J, Lachmann F, Feldstein S, Crown C, Jasnow J. Systems models in development and psychoanalysis: The case of vocal rhythm coordination and attachment. Infant Mental Health Journal. 2000; 21:99-122.

Beebe B, Jaffe J, Markese S, Buck K, Chen H, Cohen P, et al. The origins of 12-month attachment: A microanalysis of 4-month mother-infant interaction. Attachment and Human Development. 2010; 12(1-2):1-135. [PubMed: 20390523] 
Beebe, B.; Lachmann, F. Infant research and adult treatment: Co-constructing interactions. Hillsdale, NJ: Analytic Press; 2002.

Beebe, B.; Margolis, A.; Markese, S.; Jaffe, J.; Buck, K.; Chen, H., et al. Mother-infant vs. strangerinfant: Depression and attachment. Report to the International Psychoanalytic Association. New York State Psychiatric Institute; 2009 Aug 6.

Beebe, B.; Stern, D. Engagement-disengagement and early object experiences. In: Freedman, N.; Grand, S., editors. Communicative structures and psychic structures. New York: Plenum Press; 1977. p. 35-55.

Belsky J, Rovine M, \&Taylor D. The Pennsylvania Infant and Family Development Project III- The origins of individual differences in infant-mother attachment: Maternal and infant contributions. Child Development. 1984; 55:718-728. [PubMed: 6734313]

Bigelow A. Infants' sensitivity to familiar imperfect contingencies in social interaction. Infant Behavior \& Development. 1998; 21:149-162.

Blank D. Relating mothers' anxiety and perception to infant satiety, anxiety, and feeding behavior. Nursing Research. 1986; 35:347-351. [PubMed: 3640351]

Bradley B, Mogg K. Attentional bias for emotional faces in generalized anxiety disorder. British Journal of Clinical Psychology. 1999; 38:267-278. [PubMed: 10532148]

Britton J. Pre-discharge anxiety among mothers of well newborns: Prevalence and correlates. Acta Paediatrica. 2005; 94:1771-1776. [PubMed: 16421038]

Campbell S, Cohn J. Prevalence and correlates of postpartum depression in first-time mothers. Journal of Abnormal Psychology. 1991; 100:549-599.

Campos J, Frankel C, Camras L. On the nature of emotion regulation. Child Development. 2004; 75:377-394. [PubMed: 15056194]

Chapple, E. Culture and biological man. New York: Holt, Rhinehart \& Winston; 1970.

Chen $\mathrm{H}$, Cohen P. Using individual growth model to analyze the change in quality of life from adolescence to adulthood. Health and Quality of Life Outcomes. 2006; 4:1-7. [PubMed: 16393335]

Chorpita B, Barlow D. The development of anxiety: The role of control in the early environment. Psychological Bulletin. 1998; 124:3-21. [PubMed: 9670819]

Cohen P, Beebe B. Video feedback with a depressed mother and her infant: A collaborative individual psychoanalytic and mother-infant treatment. Journal of Infant, Child, and Adolescent Psychotherapy. 2002; 2:1-55.

Cohen P, Chen H, Hamgiami F, Gordon K, McArdle J. Multilevel analyses for predicting sequence effects of financial and employment problems on the probability of arrest. Journal of Quantitative Criminology. 2000; 16:223-235.

Cohn JF, Campbell SB, Matias R, Hopkins J. Mother-infant face-to-face interactions of postpartum depressed and non-depressed mothers. Developmental Psychology. 1990; 26:15-23.

Cohn J, Elmore M. Effect of contingent changes in mother's effective expression on the organization of behavior in 3-month-old infants. Infant Behavior \& Development. 1988; 11:493-505.

Cohn J, Tronick E. Mother-infant face-to-face interaction: Influence is bidirectional and unrelated to periodic cycles in either partner's behavior. Developmental Psychology. 1988; 24:386-392.

Cole P, Martin S, Dennis T. Emotion regulation as a scientific construct: Methodological challenges and directions of child development research. Child Development. 2004; 75:317-333. [PubMed: 15056186]

Crown C, Flaspohler D, Feldstein S, Jaffe J, Beebe B, Jasnow M. Mathematical models for coordinated interpersonal timing in mother-infant interactions in the first year of life. Journal of Psycholinguistic Research. 1996; 25:617-628. [PubMed: 8946755]

Davidson R, Jackson D, Kalin N. Emotion, plasticity, context and regulation: Perspectives from affective neuroscience. Psychological Bulletin. 2000; 126:86-89.

DeCasper A, Carstens A. Contingencies of stimulation: Effects on learning and emotion in neonates. Infant Behavior \& Development. 1980; 9:19-36. 
Demetriades, H. Maternal anxiety and maternal spatial proximity in 4-month mother-infant face-toface interaction. Unpublished doctoral dissertation. CW Post Campus: Long Island University; 2003.

de Rosnay M, Cooper P, Tsigaras N, Murray L. Transmission of social anxiety from mother to infant: An experimental study using a social referencing paradigm. Behavior Research and Therapy. 2006; 44:1165-1175.

Downey G, Coyne J. Children of depressed parents: An integrated review. Psychological Bulletin. 1990; 108:50-76. [PubMed: 2200073]

Feldman R. From biological rhythms to social rhythms: Physiological precursors of mother-infant synchrony. Developmental Psychology. 2006; 4:175-188. [PubMed: 16420127]

Feldman R. Parent-infant synchrony and the construction of shared timing: Physiological precursors, developmental outcomes, and risk conditions. Journal of Child Psychology and Psychiatry. 2007; 48:329-354. [PubMed: 17355401]

Feldman R, Greenbaum C, Mayes L, Erlich S. Change in mother-infant interactive behavior: Relations to change in the mother, the infant, and the social context. Infant Behavior \& Development. 1997; 20:151-163.

Field T. Infants of depressed mothers. Infant Behavior \& Development. 1995; 18:1-13.

Field T, Healy B, Goldstein S, Guthertz M. Behavior-state matching \& synchrony in mother-infant interactions of nondepressed vs. depressed dyads. Developmental Psychology. 1990; 26:7-14.

Field T, Hernandez-Reif M, Vera Y, Gil K, Diego M, Bendell D, Yando R. Anxiety and anger effects on depressed mother-infant spontaneous and imitative interaction. Infant Behavior \& Development. 2005; 28:1-9.

Fogel, A. Two principles of communication: Co-regulation and framing. In: Nadel, J.; Camaioni, L., editors. New perspectives in early communicative development. London: Routledge; 1993. p. 9-22.

Fonagy, P.; Gergely, G.; Jurist, E.; Target, M. Affect regulation, mentalization, and the development of self. New York: Other Press; 2002.

Fox E, Russo R, Dutton K. Attentional bias for threat: Evidence for delayed disengagement from emotional faces. Cognition and Emotion. 2002; 16(3):355-379. [PubMed: 18273395]

Gianino, A.; Tronick, E. The mutual regulation model: The infant's self and interactive regulation coping and defense. In: Field, T.; McCabe, P.; Schneiderman, N., editors. Stress and coping. Hillsdale, NJ: Erlbaum; 1988. p. 47-68.

Gilboa, E.; Granat, A.; Feldman, R.; Kvint, J.; Merlov, P. Maternal depression, anxiety, and alexythemia in the post-birth period; Paper presented at the biennial meeting of the Society for Research in Emotions; New York. 2004 Jul.

Gitlin M, Pasnau R. Psychiatric syndromes linked to reproductive function in women: A review of current knowledge. American Journal of Psychiatry. 1989; 146:1413-1422. [PubMed: 2488677]

Goldstein H, Healy M, Rasbash J. Multi-level time-series models with applications to repeated measures data. Statistics in Medicine. 1994; 13:1643-1655. [PubMed: 7973240]

Gondoli D, Silverberg S. Maternal emotional distress and diminished responsiveness: The mediating role of parenting efficacy. Developmental Psychology. 1997; 33:861-868. [PubMed: 9300219]

Gottman, J. Marital interactions. New York: Academic Press; 1979.

Gottman, J. Time-series analysis. Cambridge England: Cambridge University Press; 1981.

Gusella J, Muir D, Tronick E. The effect of manipulating maternal behavior during an interaction on 3and 6-month-olds' affect and attention. Child Development. 1988; 59:1111-1124. [PubMed: 3168619]

Hains S, Muir D. Effects of stimulus contingency in infant-adult interactions. Infant Behavior \& Development. 1996; 19:49-61.

Haith M, Hazan C, Goodman G. Expectation and anticipation of dynamic visual events by 3.5 month old babies. Child Development. 1988; 59:467-479. [PubMed: 3359865]

Hane A, Feldstein S, Dernetz V. The relation between coordinated interpersonal timing and maternal sensitivity in four-month-old infants. Journal of Psycholinguistic Research. 2003; 32:525-539. [PubMed: 14564991] 
Hay, D. Postpartum depression and cognitive development. In: Murray, L.; Cooper, P., editors. Postpartum depression and child development. New York: Guilford Press; 1997. p. 85-110.

Hentel, A.; Beebe, B.; Jaffe, J. Maternal depression at 6 weeks is associated with infant self-comfort at 4 months; Poster presented at the International Conference for Infant Studies; Brighton, England. $2000 \mathrm{Jul}$.

Heron J, O'Connor T, Evans J, Golding J, Glover V. The course of anxiety and depression through pregnancy and the postpartum in a community sample. Journal of Affective Disorders. 2004; 80:65-73. [PubMed: 15094259]

Hsu H, Fogel A. Stability and transitions in mother-infant face-to-face communication during the first 6 months: A microhistorical approach. Developmental Psychology. 2003; 39:1061-1082. [PubMed: 14584985]

Jaffe J, Beebe B, Feldstein S, Crown CL, Jasnow M. Rhythms of dialogue in infancy. Monographs of the Society for Research in Child Development. 2001; 66(2, Serial No. 264):1-132.

Kaitz M, Maytal H. Interactions between anxious mothers and their infants: An integration of theory and research. Infant Mental Health Journal. 2005; 26:570-597.

Kaitz M, Maytal H, Devor N, Bergman L, Mankuta D. Maternal anxiety, mother-infant interactions, and infants' response to challenge. Infant Behavior \& Development. 2010; 33:136-148. [PubMed: 20116860]

Kaufman J, Charney D. Co-morbidity of mood and anxiety disorders. Depression and Anxiety. 2000; 12:69-76. [PubMed: 11098417]

Keller H, Lohaus A, Volker S, Cappenberg M, Chasiotis A. Temporal contingency as an independent component of parenting behavior. Child Development. 1999; 70:474-485.

Koulomzin M, Beebe B, Anderson S, Jaffe J, Feldstein S, Crown C. Infant gaze, head, face, and selftouch at four months differentiate secure vs. avoidant attachment at one year: A microanalytic approach. Attachment and Human Development. 2002; 4:3-24. [PubMed: 12065027]

Kushnick, G. Maternal spatial intrusion patterns in mother-infant face-to-face play: Maternal dependency, depression, and mother-infant chase and dodge. Unpublished doctoral dissertation. New York: Long Island University; 2002.

Lewis M, Feiring C. Infant, mother and mother-infant interaction behavior and subsequent attachment. Child Development. 1989; 60:831-837.

Lewis M, Goldberg S. Perceptual-cognitive development in infancy: A generalized expectancy model as a function of the mother-infant interaction. Merrill-Palmer Quarterly. 1969; 15:81-100.

Leyendecker B, Lamb M, Fracasso M, Scholmerich A, Larson D. Playful interaction and the antecedents of attachment: A longitudinal study of Central American and Euro-American mothers and infants. Merrill-Palmer Quarterly. 1997; 43:24-27.

Littell, R.; Milliken, G.; Stoup, W.; Wolfinger, R. SAS system for mixed models. Cary, NC: SAS Institute; 1996.

Lyons-Ruth K, Bronfman E, Parsons E. Maternal frightened, frightening, or atypical behavior and disorganized infant attachment patterns. Monographs of the Society for Research in Child Development. 1999; 64(3, Serial No. 258):67-96. [PubMed: 10597543]

Lyons-Ruth, K.; Zoll, D.; Connell, D.; Grunebaum, H. The depressed mother and her one-year-old infant: Environment, interaction, attachment and infant development. In: Tronick, E.; Fields, T., editors. Maternal depression and infant disturbance: New directions for child development. San Francisco: Jossey Bass; 1986. p. 61-82.

Malatesta C, Culver C, Tesman J, Shepard B. The development of emotion expression during the first two years of life. Monographs of the Society for Research in Child Development. 1989; 54(1-2): 1-103. (Serial No. 219). [PubMed: 2770755]

Markese, S.; Beebe, B.; Jaffe, J.; Feldstein, S. Rhythms of dialogue in infancy and attachment narratives in childhood; Poster presented at the International Conference of Infant Studies; Vancouver, Canada. 2008 Mar.

Matthey S, Barnett B, Howie P, Kavanagh D. Diagnosing postpartum depression in mothers and fathers: Whatever happened to anxiety? Journal of Affect Disorders. 2003; 74:139-147. 
McArdle, J.; Bell, R. An introduction to latent growth models for developmental data analysis. In: Little, T.; Schnabel, K.; Baumert, J., editors. Modeling longitudinal and multilevel data: Practical issues, applied approaches, and specific examples. Mahwah, NJ: Erlbaum; 2000. p. 69-107.

Mertesacker B, Bade U, Haverkock A, Pauli-Pott U. Predicting maternal reactivity/sensitivity: The role of infant emotionality, maternal depressiveness/anxiety, and social support. Infant Mental Health Journal. 2004; 25:47-61.

Messinger D. Positive and negative: Infant facial expressions and emotions. Current Directions in Psychological Science. 2002; 11:1-6.

Miller R, Pallant J, Negri L. Anxiety and stress in the postpartum: Is there more to postnatal distress than depression? BMC Psychiatry. 2006; 6:1-11. [PubMed: 16396684]

Monk C, Myers M, Sloan R, Ellman L, Fifer W. Effects of women's stress elicited physiological activity and chronic anxiety on fetal heart rate. Journal of Developmental \& Behavioral Pediatrics. 2003; 24:32-38. [PubMed: 12584483]

Moreno A, Posada G, Goldyn D. Presence and quality of touch influence coregulation in mother-infant dyads. Infancy. 2006; 9:1-20.

Muir, D.; Hains, S. Infantile sensitivity to perturbations in adult facial, vocal, tactile, and contingent stimulation during face-to-face interaction. In: DeBoysson-Bardies, B.; DeSchonen, S.; Jusczyk, P.; McNeilage, P.; Morton, J., editors. Developmental neurocognition: Speech and face processing in the first year of life. Dordrecht, The Netherlands: Kluwer Academic; 1993. p. 171-185.

Murray, L.; Cooper, PJ. The role of infant and maternal factors in postpartum depression, motherinfant interactions, and infant outcomes. In: Murray, L.; Cooper, PJ., editors. Postpartum depression and child development. New York: Guilford Press; 1997. p. 111-135.

Murray L, Cooper P, Creswell C, Schofield E, Sack C. The effects of maternal social phobia on mother-infant interactions and infant social responsiveness. Journal of Child Psychology and Psychiatry. 2007; 48:45-52. [PubMed: 17244269]

Murray L, Fiori-Cowley A, Hooper R, Cooper P. The impact of postnatal depression and associated adversity on early mother-infant interactions and later infant outcome. Child Development. 1996; 67:2512-2526. [PubMed: 9022253]

Murray, L.; Trevarthen, C. Emotional regulation of interactions between two-month-olds and their mothers. In: Field, T.; Fox, N., editors. Social perception in infants. Norwood, NJ: Ablex; 1985. p. 177-197.

Nicol-Harper R, Harvey A, Stein A. Interactions between mothers and infants: Impact of maternal anxiety. Infant Behavior \& Development. 2007; 30:161-167. [PubMed: 17292789]

Nitschke JB, Heller W, Imig JC, McDonald RP, Miller GA. Distinguishing dimensions of anxiety and depression. Cognitive Therapy and Research. 2001; 25(1):1-22.

O'Connor T, Heron J, Golding J, Beveridge M, Glover V. Maternal antenatal anxiety and children's behavioural/emotional problems at 4 years. British Journal of Psychiatry. 2002; 180:502-508. [PubMed: 12042228]

Ohman C. Automaticity and the amygdala: Nonconscious responses to emotional faces. Current Directions in Psychological Science. 2002; 11:62-66.

Papousek M, von Hofacker N. Persistent crying in early infancy: A non-trivial condition of risk for the developing mother-infant relationship. Child: Care, Health, and Development. 1998; 24:395-424.

Pelaez-Nogueras M, Field T, Hossain Z, Pickens J. Depressed mothers' touch increases infant positive affect and attention in still-face interactions. Child Development. 1996; 67:1780-1792. [PubMed: 8890507]

Pickens J, Field T. Facial expressivity in infants of "depressed" mothers. Developmental Psychology. 1993; 29:986-988.

Pizzagalli D, Nitschke J, Oakes T, Hendrick A, Horras K, Larson C, et al. Brain electrical tomography in depression: The importance of symptom severity, anxiety, and melancholic features. Biological Psychiatry. 2002; 52(2):73-85. [PubMed: 12113998]

Porter CL, Hsu H. First-time mothers' perceptions of efficacy during the transition to motherhood: Links to infant temperament. Journal of Family Psychology. 2003; 17:54-64. [PubMed: 12666463] 
Roe K, Roe A, Drivas A, Bronstein K. A curvilinear relationship between maternal vocal stimulation and 3 month olds' cognitive processing. Infant Mental Health Journal. 1990; 2:175-189.

Sander, L. The regulation of exchange in the infant-caretaker system and some aspects of the contextcontent relationship. In: Lewis, M.; Rosenblum, L., editors. Interaction, conversation, and the development of language. New York: Wiley; 1977. p. 133-156.

Shackman J, Pollak S. Experiential influences on multimodal perception of emotion. Child Development. 2005; 76:1116-1126. [PubMed: 16150006]

Shedler J, Mayman M, Manis M. The illusion of mental health. American Psychologist. 1993; 48:1117-1131. [PubMed: 8259825]

Singer J. Using SAS PROC MIXED to fit multilevel models, hierarchical models, and individual growth models. Journal of Educational and Behavioral Statistics. 1998; 24:323-355.

Spielberger, C.; Gorsuch, R.; Lushene, R. STAI Manual for the State Trait Anxiety Inventory. Palo Alto, CA: Consulting Psychologists Press; 1983.

Stack, D. The salience of touch and physical contact during infancy: Unraveling some of the mysteries of the somasthetic sense. In: Bremner, G.; Fogel, A., editors. Blackwell handbook of infant development: Handbooks of developmental psychology. Malden, MA: Blackwell; 2001. p. 351-378.

Stack D, Arnold S. Changes in mothers' touch and hand gestures influence infant behavior during face-to-face exchanges. Infant Behavior \& Development. 1998; 21(3):451-468.

Stack D, Muir D. Adult tactile stimulation during face-to-face interactions modulates 5-month olds' affect and attention. Child Development. 1992; 63:1509-1525. [PubMed: 1446566]

Stepakoff, S.; Beebe, B.; Jaffe, J. Mother-infant tactile communication at four months: The roles of infant gender, maternal ethnicity, and maternal depression; Poster presented at the International Conference of Infant Studies; Brighton, England. 2000 Jul.

Stern D. A microanalysis of mother-infant interaction. Journal of the American Academy of Child Psychiatry. 1971; 19:501-517. [PubMed: 5168603]

Stern, D. The interpersonal world of the infant. New York: Basic Books; 1985.

Stern, D. The motherhood constellation. New York: Basic Books; 1995.

Tarabulsy G, Tessier R, Kappas A. Contingency detection and the contingent organization of behavior interactions: Implications for socioemotional development in infancy. Psychological Bulletin. 1996; 120:25-41. [PubMed: 8711014]

Teti D, Gelfand D. Behavioral competence among mothers of infants in the first year: The mediational role of maternal self-efficacy. Child Development. 1991; 62:908-929.

Thomas E, Malone T. On the dynamics of two person interactions. Psychological Review. 1979; 86:331-360.

Thomas E, Martin J. Analyses of parent-infant interaction. Psychological Review. 1976; 83:141-155.

Tomlinson M, Cooper P, Murray L. The mother-infant relationship and infant attachment in a South African peri-urban settlement. Child Development. 2005; 76:1044-1054. [PubMed: 16150001]

Trevarthen, C. Descriptive analyses of infant communicative behavior. In: Schaffer, H., editor. Studies in mother-infant interaction. London: Academic Press; 1977. p. 227-270.

Tronick E. Emotions and emotional communication in infants. American Psychologist. 1989; 44:112119. [PubMed: 2653124]

Tronick E, Beeghly M, Weinberg K, Olson K. Postpartum exuberance: Not all women in a highly positive emotional state in the postpartum period are denying depression and distress. Infant Mental Health Journal. 1997; 18:406-423.

Tronick, E.; Weinberg, M. The infant regulatory scoring system. Boston: Children's Hospital, Harvard Medical School; 1990.

Van Egeren L, Barratt M, Roach M. Mother-infant responsiveness: Timing, mutual regulation, and interactional context. Developmental Psychology. 2001; 37:684-697. [PubMed: 11552763]

Warner R. Sequential analysis of social interaction: Assessing internal versus social determinants of behavior. Journal of Personality Social Psychology. 1992; 63:51-60. 
Warner R, Malloy D, Schneider K, Knoth R, Wiler B. Rhythmic organization of social interaction and observer ratings of positive affect and involvement. Journal of Nonverbal Behavior. 1987; 11:5774.

Warren S, Gunnar M, Kagan J, Anders T, Simmens S, Rones M, et al. Maternal panic disorder: Infant temperament, neurophysiology, and parenting behavior. Journal of the American Academy of Child and Adolescent Psychiatry. 2003; 42:814-825. [PubMed: 12819441]

Watson, J. Contingency perception in early social development. In: Field, T.; Fox, N., editors. Social perception in infants. Norwood, NJ: Ablex; 1985. p. 157-176.

Weinberg MK, Beeghly M, Olson KL, Tronick EZ. Effects of maternal depression and panic disorder on mother-infant interactive behavior in the face-to-face still-face paradigm. Infant Mental Health Journal. 2008; 29:472-491. [PubMed: 21731149]

Weinberg K, Olson K, Beeghly M, Tronick E. Making up is hard to do, especially for mothers with high levels of depressive symptoms and their infant sons. Journal of Child Psychology and Psychiatry. 2006; 47:670-683. [PubMed: 16790002]

Weinberg K, Tronick E. Beyond the face: An empirical study of infant affective configurations of facial, vocal, gestural, and regulatory behaviors. Child Development. 1994; 65:1503-1515. [PubMed: 7982365]

Weinberg K, Tronick E. Infant affective reactions to the resumption of maternal interaction after the still face. Child Development. 1996; 96:905-914. [PubMed: 8706534]

Weinberg K, Tronick E. The impact of maternal psychiatric illness on infant development. Journal of Clinical Psychiatry. 1998; 59:53-61. [PubMed: 9559760]

Weinstein, E.; Kahn, R. Denial of illness. Springfield, IL: Thomas; 1955.

Wijnroks L. Maternal recollected anxiety and mother-infant interaction in preterm infants. Infant Mental Health Journal. 1999; 20:393-409.

Yale M, Messinger D, Cobo-Lewis A, Delgado C. The temporal coordination of early infant communication. Developmental Psychology. 2003; 39:815-824. [PubMed: 12952396] 


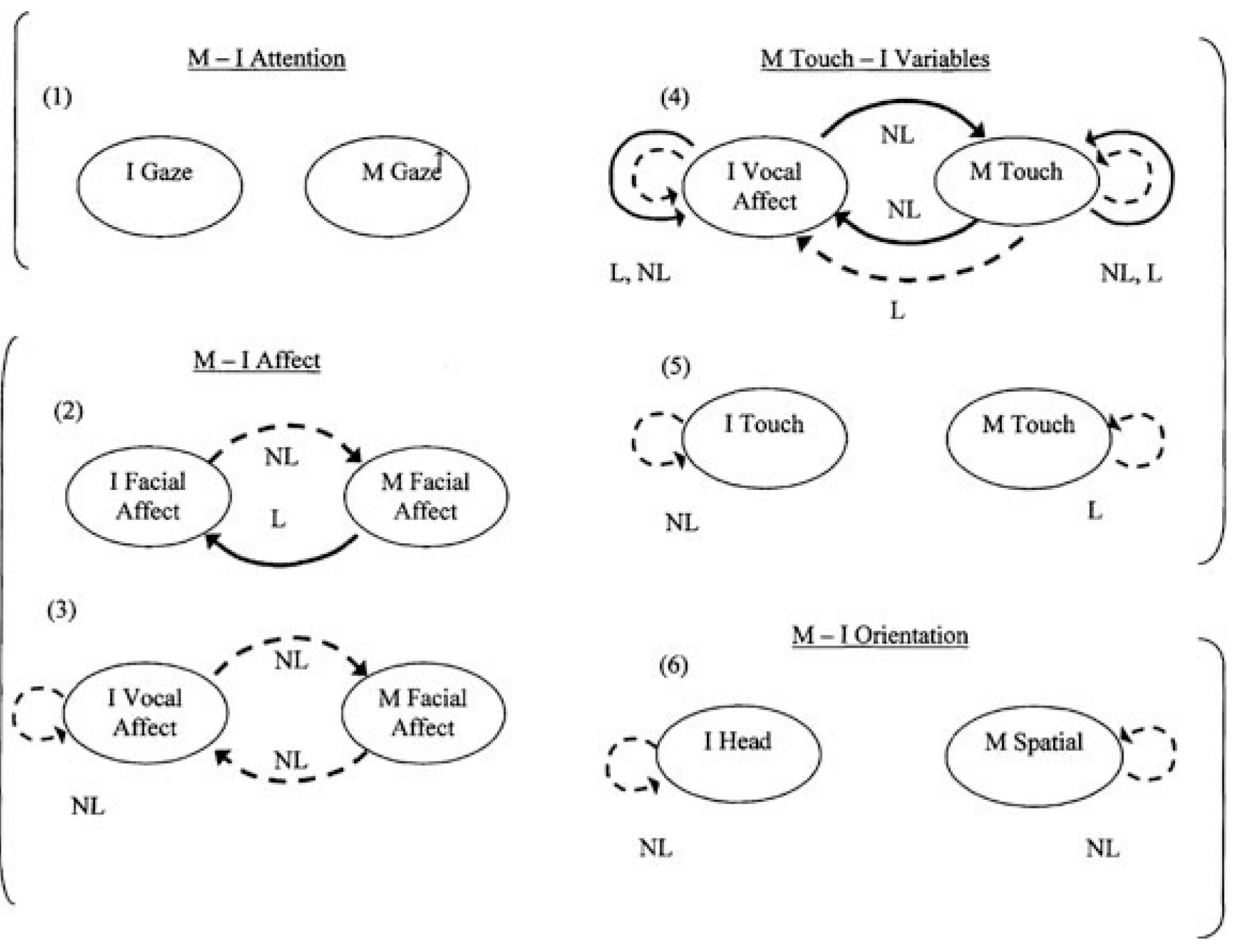

Figure 1.

Associations of Increasing Maternal Anxiety with Mother and Infant Self- and Interactive Contingency

1. Summary of all linear (L) and nonlinear (NL) (Table 1) associations of maternal anxiety (SAT, Spielberger Trait) with self- and interactive contingency; NL findings for high end of anxiety only; $\mathrm{L}+\mathrm{NL}$ indicates effects that are both linear and nonlinear; Face $=$ Facial Affect, VcA = Vocal Affect, Tch $=$ Touch, I Head = Infant Head Orientation, M Sptl = Mother Spatial Orientation.

2. $\quad \mathrm{I} \rightarrow \mathrm{M}=$ Infant behavior (lagged) predicts Mother behavior (current second), i.e., "Mother coordinates with Infant;" M $\rightarrow$ I= Mother behavior (lagged) predicts Infant behavior (current second), i.e., "Infant coordinates with Mother."

3. ---> As maternal anxiety increases, contingency is lower, by multi-level regression models.

4. $\rightarrow$ As maternal anxiety increases, contingency is higher, by multi-level regression models. 
5. If NO ARROW: No significant effects of maternal anxiety.

6. (1)-(6) indicate the 6 modality pairings examined, grouped by domains: attention (pattern 1), affect $(2,3)$, mother touch $(4,5)$, spatial orientation (6).

7. $\uparrow$ Indicates greater percent time mother gazing at infant face in more anxious mothers. 


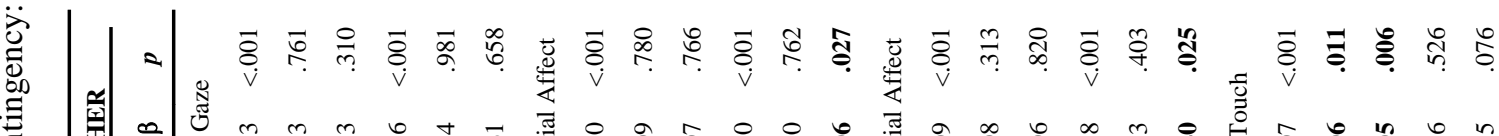

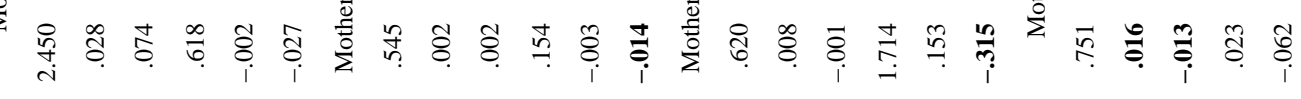



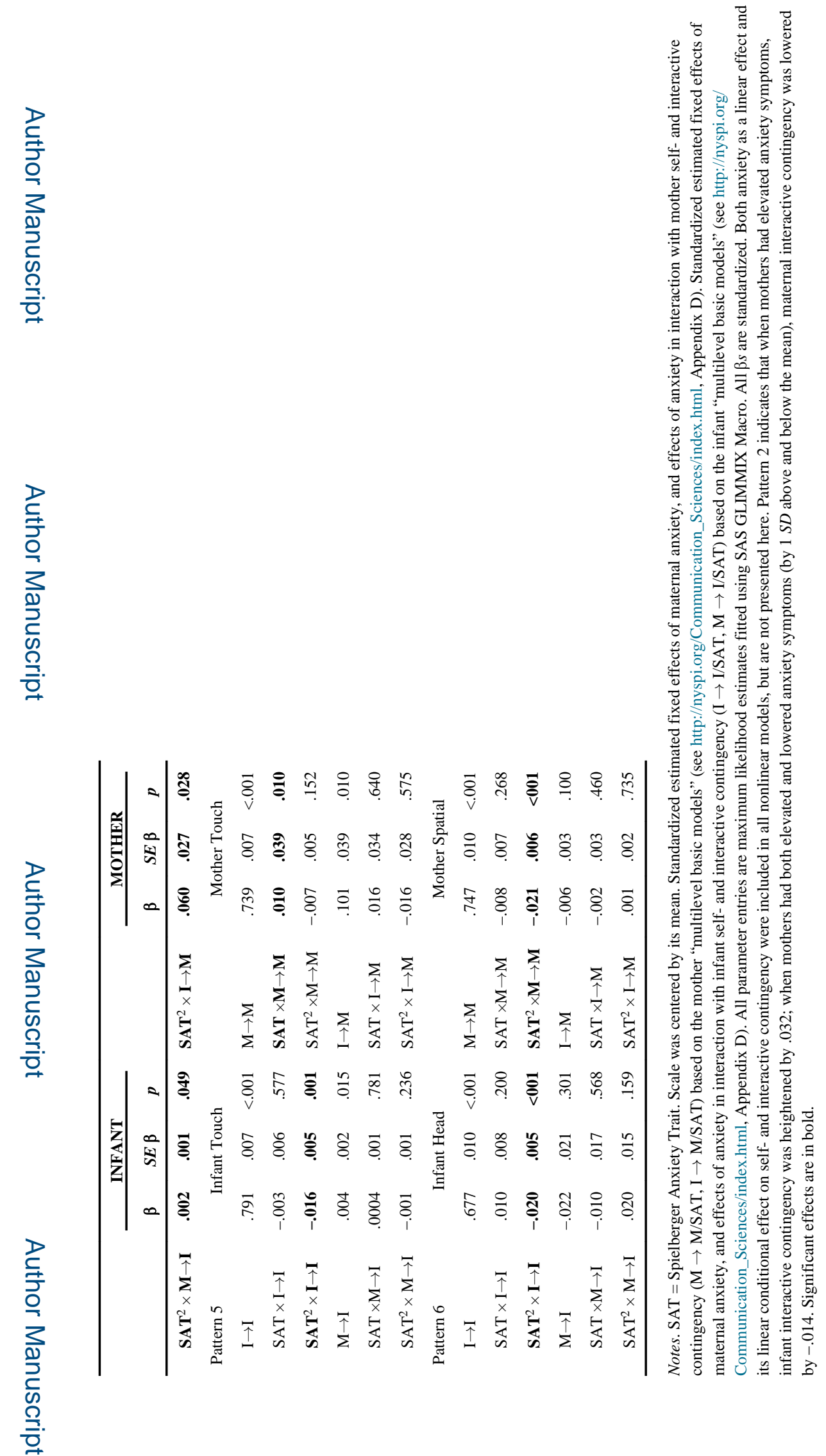